\title{
The Hippocampal/Parahippocampal Regions and Recognition Memory: Insights from Visual Paired Comparison versus Object-Delayed Nonmatching in Monkeys
}

\author{
Sarah Nemanic, Maria C. Alvarado, and Jocelyne Bachevalier \\ Department of Neurobiology and Anatomy, University of Texas Health Science Center, Houston, Texas 77030
}

\begin{abstract}
Recognition memory was assessed by submitting the same adult monkeys to visual paired comparison (VPC) with mixed delays (10-120 sec), followed by three consecutive versions of object-delayed nonmatching-to-sample (DNMS): increasing delays ( $10-600 \mathrm{sec}$ ), lengthened lists (3-10 objects), and intervening distractors in the delays (light at $10 \mathrm{sec}$, motor task at $30-600 \mathrm{sec}$, or context change at $600 \mathrm{sec}$ ). Four groups were tested: normal controls, monkeys with ibotenic acid lesions of the hippocampal formation $(\mathrm{H})$, and monkeys with aspiration lesions of either the perirhinal (PRh) or parahippocampal (areas TH/TF) cortex. Group H was impaired on VPC at delays $\geq 60$ sec but had difficulty on DNMS only at $600 \mathrm{sec}$ delays with distraction. In group TH/TF, the VPC impairment emerged earlier (30 sec); yet, once the nonmatching rule was mastered, no significant change occurred on any DNMS condition. Only group PRh behaved congruently on VPC and DNMS, exhibiting a deficit at the easiest condition that worsened with increasing delays as well as in DNMS lengthened list and distraction conditions. These results led us to postulate that VPC and DNMS, as previously administered to monkeys, were not equivalent visual recognition memory probes. Specifically, we propose that, for VPC, because of passive (incidental) encoding, the animal's performance rests on both item familiarity and event recollection, whereas, for DNMS, because of active (purposeful) encoding, performance relies more on item familiarity. This proposal converges with current models postulating distinct, but interactive, mnemonic roles for the hippocampal and adjacent TH/TF regions.
\end{abstract}

Key words: familiarity; recollection; perirhinal; associative recognition; incidental learning; intentional learning

\section{Introduction}

The last decade has provided ample evidence that, within the medial temporal lobe, recognition memory, which includes both familiarity judgment and recollection (Tulving, 1985; Yonelinas, 2002), requires not only the hippocampal region (Ammon fields, dentate gyrus, and subicular complex), but also the adjacent cortical areas [entorhinal, perirhinal (PRh), and parahippocampal (areas TH/TF) cortices] (for review, see Murray, 2000). The question now becomes whether recognition memory emerges from

Received Aug. 12, 2003; revised Dec. 15, 2003; accepted Dec. 16, 2003.

This work was supported by Awards MH-58846 from the National Institute of Mental Health (NIMH) and HD35471 from the National Institute of Child Health and Human Development to J.B. and by Predoctoral National Research Service Award MH-12106 from NIMH to S.N. The data served as partial fulfillment of the requirements for the Ph.D. degree from The University of Texas Graduate School of Biomedical Sciences at Houston to S.N. We express our appreciation to the veterinary staff for expertise and valuable help in the presurgical and postsurgical care of the monkeys, Roger E. Price and Belinda Rivera for the care and handling of the animals during the MR imaging procedures, and Edward F. Jackson for expert assistance in neuroimaging scanning techniques. We also thank Martine Meunier and Ludise Málková for invaluable suggestions and discussions on previous versions of this manuscript, Mortimer Mishkin for providing some of the monkeys participating in the experiments, Anupa Prabhudesa and Andy Kazama for scoring behavioral data as second observers, Fernando Latunio for histological preparation of the brains, and Lorenzo Morales for the illustrations.

Correspondence should be addressed to Dr. Jocelyne Bachevalier, Department of Neurobiology and Anatomy, University of Texas Health Science Center, 6431 Fannin Street, Houston, TX 77030. E-mail: Jocelyne.Bachevalier@uth.tmc.edu.

DOI:10.1523/JNEUROSCI.3763-03.2004

Copyright $\odot 2004$ Society for Neuroscience $\quad 0270-6474 / 04 / 242013-14 \$ 15.00 / 0$ cooperative interactions among relatively specialized medial temporal lobe components (Brown and Aggleton, 2001; Yonelinas, 2002) or, alternatively, is distributed throughout a functionally unitary hippocampal/parahippocampal region (Manns et al., 2003).

Two tasks have been used to investigate recognition memory in monkeys: object-delayed nonmatching-to-sample (DNMS) and visual paired comparison (VPC). Both tasks use familiarization to a single item, followed by a choice phase, during which the familiar item is presented with a new one. For VPC, animals passively view black/white stimuli on a screen, and recognition is inferred when animals look longer at the novel stimulus. For DNMS, a novelty-reward association is gradually taught to animals that actively interact, visually and manually, with objects, and selection of the novel item indicates recognition. On the surface, it seems that both tasks should require similar cognitive processes for performance, and damage-impairing performance on one task should produce the same impairment on the other. This prediction has proven to be true for damage to the PRh cortex, which affects performance on both tasks but not for damage to the hippocampal formation (for review, see Baxter and Murray, 2001; Bachevalier et al., 2002). Indeed, selective hippocampal lesions yield no, or moderate, impairment on DNMS but severe recognition loss on VPC. Given the similarities be- 
tween the two recognition tasks, the different outcome of hippocampal lesions suggests that the recognition processing ability measured by the VPC and DNMS tasks might differentially engage the hippocampal formation. These conclusions drawn from comparisons across different studies are informative but could be misleading because of significant variations in lesion extent and behavioral procedures between studies. Thus, to examine this issue further, the present within-study design compared performance of monkeys with selective lesions of either the hippocampal formation, PRh cortex, parahippocampal areas TH/TF, or none on three tasks of object recognition memory: the VPC, DNMS, and a variant of the DNMS task in which distractors were systematically introduced within the delay period of the trials.

\section{Materials and Methods \\ Subjects}

Subjects were 15 rhesus monkeys (Macaca mulatta) (6-12 years of age) of both sexes, weighing 5-12 kg. Four monkeys (one male and three females) had received bilateral neurotoxic lesions of the hippocampal formation $(\mathrm{H})$, five (two males and three females) had received aspiration lesions of the PRh cortex, and three (two males and one female) had received aspiration lesions of cortical areas TH and TF on the parahippocampal gyrus. The remaining three monkeys (two males and one female) were unoperated controls $(\mathrm{N})$. Animals were housed individually and maintained on a $12 \mathrm{hr}$ light/dark cycle. Multi-vitamins were given daily and fresh fruit weekly. For VPC, food (Purina Monkey Chow) was provided ad libitum, and water was available only for $12 \mathrm{hr}$ daily after completion of behavioral testing. For DNMS, water was always available, and food was given only once daily, after testing. Food rations were adjusted individually to provide the maximum amount compatible with rapid responding during testing, while ensuring that the animals remained over $90 \%$ of their free-feeding weight. The study was approved by the Institutional Animal Care and Use Committee of the University of Texas Health Science Center at Houston and took place 2 years after surgery, after testing on transverse patterning (Alvarado et al., 1998; Alvarado and Bachevalier, 2003).

\section{Neuroimaging}

MR imaging (MRI) procedures were detailed in a previous study (Nemanic et al., 2002) involving present cases $\mathrm{H}-1$ and $\mathrm{H}-2$ (as well as case $\mathrm{H}-3$, which was not behaviorally tested and, thus, was excluded from the present study). Each operated animal received two T1-weighted, whole-brain structural MR scans (coronal slices, $1 \mathrm{~mm}$ thickness) while placed in a nonferromagnetic stereotaxic device (Crist Instruments, Damascus, MD). The first scanning procedure was given 1-3 weeks before surgery to calculate the coordinates of the injection sites for neurotoxic lesions or to visualize the sulcal borders of the target region for cortical aspiration lesions. The second scan procedure took place approximately 1 year after surgery and was used to quantify hippocampal shrinkage or to estimate the extent of the PRh and parahippocampal removals. Monkeys $\mathrm{H}-1$ and $\mathrm{H}-2$ received an additional MR scanning procedure $7-10 \mathrm{~d}$ after surgery, including a T1-weighed structural MR scan, followed by a fluid attenuated inversion recovery (FLAIR) protocol to visualize waterdensity hypersignals that constitutes a rapid and accurate way to quantify location and extent of neurotoxin diffusion (Málková et al., 2001b; Nemanic et al., 2002).

\section{Surgery}

All surgical procedures were performed under deep anesthesia [7:3 mixture of ketamine hydrochloride $(100 \mathrm{mg} / \mathrm{ml})$ and Robinul $(0.2 \mathrm{mg} / \mathrm{ml}$; $0.1 \mathrm{ml} / \mathrm{kg}$, i.m.), followed by $2 \%$ isofluorane inhalation to effect] using aseptic conditions. The animal was repositioned in the stereotaxic apparatus (group H) or secured in a head holder (groups PRh and TH/TF). Heart and respiration rates, blood pressure, expired $\mathrm{CO}_{2}$, and body temperature were monitored. After disinfection (Nolvasan solution) of the scalp and application of local anesthetic ( $1.5 \mathrm{ml}$ of $25 \%$ Marcaine) along the incision line, the skin was cut from a midpoint between the supraorbital ridges to the occiput (groups $\mathrm{H}$ and TH/TF), or from the right to the left zygomatic arch (group PRh). Then, the connective tissue and temporal muscles were retracted gently, the bone was removed, and the dura was cut. When the lesions were completed, the dura openings were sewn, and all tissues were closed in anatomical layers. To minimize brain swelling, all operated animals received an intravenous drip of $30 \mathrm{ml}$ of Mannitol ( $20 \%$; delivered at a rate of $1 \mathrm{ml} / \mathrm{min}$ ) either before the final neurotoxin injection or midway through the aspiration surgeries. Beginning 12 $\mathrm{hr}$ before and continuing for 1 week after surgery, all operated monkeys were treated with dexamethasone sodium phosphate $(0.4 \mathrm{mg} / \mathrm{kg}$, i.m. and Cephazolin ( $25 \mathrm{mg} / \mathrm{kg}$, i.m.; Bristol-Myers Squibb) to reduce inflammation and protect against infection, respectively. For $3 \mathrm{~d}$ after surgery, the monkeys also received an analgesic (acetaminophen; $10 \mathrm{mg} / \mathrm{kg}$, p.o.).

Hippocampal lesions. The lesions were intended to include all ammonic fields, the dentate gyrus, and the prosubiculum and subiculum (Fig. 1, left). The number of injection sites and their positions in the anterior-posterior (AP), medial-lateral, and dorsal-ventral planes were determined for each animal based on the preoperative MR structural images. The MRI coordinates of the selected sites were then converted into stereotaxic coordinates relative to the stereotaxic point zero. A bone flap was made on the top of the skull, and small slits were cut in the dura at appropriate locations. At each site, the needle of a $10 \mu \mathrm{l}$ Hamilton syringe held in a Kopf electrode manipulator (David Kopf Instruments, Tujunga, CA) was lowered slowly, and, after completion of the injection, left in place for $5 \mathrm{~min}$ to permit diffusion of the neurotoxin and minimize its spread along the needle track. The needle was then swabbed to remove any residual neurotoxin, repositioned, and lowered to the next site. For cases H-1 and H-2 (Nemanic et al., 2002), the two hippocampi simultaneously received nine injections in the center of the body and two additional injections at the uncus (spaced $1.5 \mathrm{~mm}$ apart in the AP plane) of $2.4 \mu \mathrm{l}$ of ibotenic acid (10 $\mathrm{mg} / \mathrm{ml}$ in PBS, pH 7.4; Biosearch Technologies, Novato, CA) each at a rate of $0.4 \mu \mathrm{l} / \mathrm{min}$. Case $\mathrm{H}-2$ underwent a second surgery 3 months after the first, to target spared hippocampal tissue revealed by the $7 \mathrm{~d}$ postoperative FLAIR MRI scan. For cases H-4 and H-5, the left and right hippocampi successively received six injections (spaced $3 \mathrm{~mm}$ apart along the AP axis) of $2 \mu \mathrm{l}$ of ibotenic acid (15 mg/ml in PBS, pH 7.4; Regis Chemical, Morton Grove, IL) each at a rate of $0.2 \mu \mathrm{l} / \mathrm{min}$.

PRh cortex lesions. Bilateral aspirations of the PRh cortex were also performed in one stage, using procedures developed by Meunier et al. (1993). The lesion was intended to include Broadman's areas 35 and 36 (see Fig. 4, left). The zygomatic arch and the bone over the ventrolateral surface of the frontotemporal junction were removed. For the rostral portion of the lesion, the dura was cut in a crescent over the frontal and temporal lobes and the frontal lobe above the orbit was elevated slightly to expose the medial temporal pole. The pia matter on the lateral lip of the rhinal sulcus was cauterized as far posterior as the rhinal sulcus could be seen, after which the lateral bank of the rhinal sulcus as well as a $2 \mathrm{~mm}$ strip of cortical tissue lateral to it was aspirated using a small gauge sucker. To access the caudal portion of the PRh cortex, the head-holder was rotated until the monkey's head was tilted at an angle of $120^{\circ}$ from the upright position, and a second incision was made in the dura over the lateral temporal lobe. The base of the temporal lobe was reflected to visualize the posterior end of the rostral removal. The pia matter on the lateral lip of the rhinal sulcus was cauterized, and the cortex on the lateral bank of the rhinal sulcus as well as $2 \mathrm{~mm}$ of tissue lateral to it was aspirated until reaching the posterior tip of the rhinal sulcus.

Parahippocampal cortex lesions. The lesions were intended to include both areas TH and TF (von Bonin and Bailey, 1947). One-stage bilateral aspiration was performed using a supralabyrinthine approach. A bone flap was made over the ventrolateral surface of the temporal lobe, and the dura was cut in a crescent over the fronto-temporal region. The borders of the lesion (see Fig. 7, left) included the lip of the medial bank of the occipitotemporal sulcus laterally, the brain stem medially, and the posterior tip of the rhinal sulcus rostrally. Caudally, the posterior middle temporal sulcus was identified and its midpoint was localized. A virtual line was drawn from this midpoint until it intersected with the occipitotemporal sulcus. The intersection was marked with the cautery and used as the most posterior extent of the TH/TF lesions. 


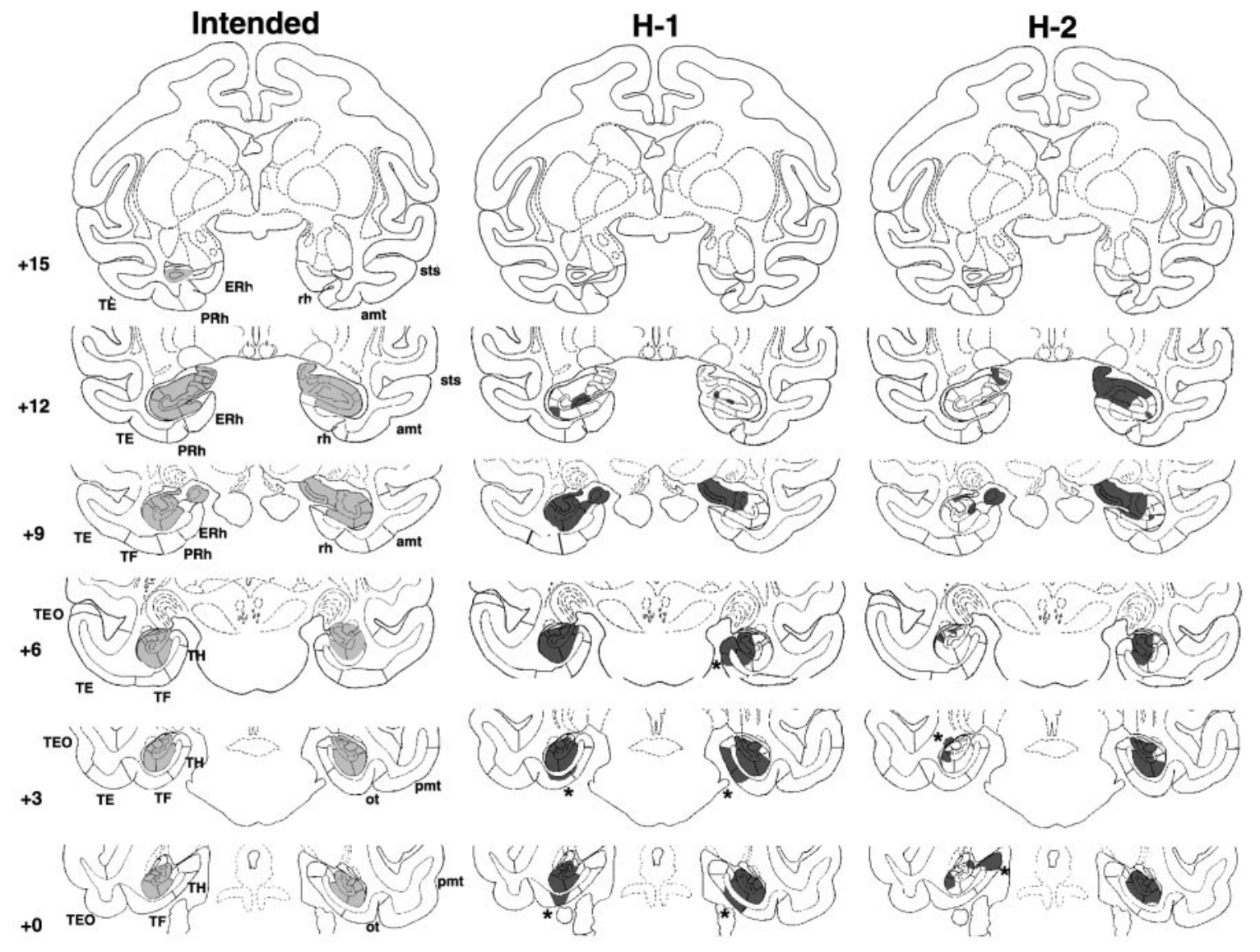

Figure 1. Coronal sections through the hippocampal formation depicting the intended damage (left), shown in gray, and actual damage in cases $\mathrm{H}-1$ and $\mathrm{H}-2$ with neurotoxic lesions of the hippocampal formation, shown in black. The numerals on the left of each coronal section of the intended lesions indicate the distance in millimeters from the interaural plane. The asterisks point to unintended damage to adjacent structures. amt, Anterior middle temporal sulcus; ERh, entorhinal cortex; pmt, posterior middle temporal sulcus; rh, rhinal sulcus; ot, occipitotemporal sulcus; sts, superior temporal sulcus; TE, TEO, TH and TF, cytoarchitectonic fields described by von Bonin and Bailey (1947).

\section{Behavioral procedures}

Apparatus and materials. Behavioral testing was performed in a standard Wisconsin General Testing Apparatus (WGTA), which was located in a darkened room equipped with a white noise generator.

For VPC, the animal was placed in a Plexiglas primate cage equipped with a sipper tube attached to the front wall of the cage, $\sim 2$ feet above its floor. Both the inner and outer screens of the WGTA were raised. The cage was positioned in the WGTA $\sim 40 \mathrm{~cm}$ in front of a translucent screen, onto which stimuli were back projected. A video camera was mounted on a tripod behind the screen and above the slide projector and positioned to clearly visualize and record the monkey's eye movements. The output of the camera was fed into a time-date generator that was connected to both a television for online monitoring of gaze direction and a video recording system for data collecting. The stimuli were black and white pictures of common objects, appearing $10 \mathrm{~cm}$ wide and $15 \mathrm{~cm}$ high on the projection screen. Pictures were organized by pairs, and the size and brightness of the pictured objects were kept uniform within a pair. Each pair of pictures was used only once during the entire task (trial-unique stimuli stricto sensu).

For DNMS, a metal transport cage was used, the front bars of which allowed the animal to reach for and displace the stimuli presented on the test tray. During stimuli presentation, only the inner opaque screen of the WGTA was raised, and the experimenter monitored the animal's behavior through the outer screen. The test area was illuminated, but the monkey's compartment was kept unlit in all testing conditions but one (see d-DNMS Type 1 below). The test area was equipped with a tray containing a row of three food wells, spaced $14 \mathrm{~cm}$ apart. The stimuli consisted of 1200 actual common objects that varied widely in color, shape, size, and texture and were organized in bins of 20 objects each. The bins were used in sequence, thus $\sim 1$ month elapsed before reuse of the objects from a given bin (trial-unique stimuli lato sensu).

VPC task. An adaptation period of 4-5 d was given to accustom the monkey to sit quietly in the front of the cage while occasionally receiving fruit juice from the sipper tube to maintain the animal's focus on passively viewing the stimuli displayed onto the screen. Then, formal testing was initiated. Each trial began with a familiarization phase that lasted until the monkey had looked at a sample picture, presented at the center of the projection screen, for a cumulative $30 \mathrm{sec}$. After a variable delay, the same picture and a new one were displayed side by side on the screen, separated by a $13.5 \mathrm{~cm}$ gap. The retention phase consisted of two such tests, lasting $5 \mathrm{sec}$ each and separated by a $5 \mathrm{sec}$ interval. The left/right position of the novel picture during the first retention test varied pseudorandomly and was reversed during the second test. Five delays were assessed in all groups $(10,20,30,60$, and $120 \mathrm{sec})$, mixed pseudorandomly within the 10 trials of each daily session. All animals were, thus, tested for a total of 50 trials (i.e., 10 trials at each delay). At the end of testing, group $\mathrm{PRh}$ received an additional session in which 10 trials of 1 sec delays were mixed pseudorandomly with trials of delays varying from 10 to $120 \mathrm{sec}$. Fruit juice was continuously available throughout the familiarization and retention phases, and monkeys could access it any time they were sitting at the sipper tube viewing pictures.

The familiarization time, which measures the actual amount of time needed to obtain the cumulative $30 \mathrm{sec}$ fixation of the sample stimulus, was recorded online while the monkeys performed the task. Furthermore, a frame-by-frame examination of the corneal reflection of the stimuli recorded on the videotapes (Pascalis and Bachevalier, 1999) was used to quantify two parameters: (1) the total retention time defined as the actual amount of time spent fixating the stimuli during the two $5 \mathrm{sec}$ 
retention tests, and (2) the percentage looking time at the novel stimulus representing the percentage of the total retention time spent fixating at the novel picture. Finally, the videotapes were also used to calculate the frequency of eye movements (number of saccades per seconds) during the retention phases. For each animal, a set of trials were analyzed by two observers, who were unaware of the animal's group and of the position of the novel stimuli, to calculate interobserver reliability (Pearson $r=0.979$ ). The remainder of the trials was analyzed by one of the two observers.

Delayed nonmatching-to-sample. DNMS testing was initiated 1-3 months after VPC completion. Because all animals had been trained before to displace objects to retrieve a food reward (Alvarado et al., 1998; Alvarado and Bachevalier, 2003), no habituation was necessary before formal testing. Typically, each trial consisted of a sample phase, in which the monkey was presented with an object covering the baited central well. Displacement of the object and retrieval of the food [a $150 \mathrm{mg}$ banana pellet (Noyes, Lancaster, $\mathrm{NH}$ ) or a raisin) initiated a delay period, followed by a choice phase, during which the nonrewarded sample object and a rewarded novel object covered the two lateral food wells. During the choice phase, the left/right position of the novel object varied pseudorandomly across trials and the animal was allowed to displace only one of the two objects. Except on one condition specifically intended to assess the effect of a context change (see d-DNMS Type 3 below), the monkey remained in the WGTA during the delay period.

In a first stage (rule learning), monkeys were taught the nonmatching principle (i.e., to associate the reward with novelty, using a $10 \mathrm{sec}$ delay between sample and choice phases). Daily sessions consisted of 20 trials separated by $30 \mathrm{sec}$ intertrial intervals. Acquisition of the rule continued until the animal reached a performance criterion of 90 correct responses in 100 consecutive trials. Then, the animals' recognition memory was further challenged using three successive versions of DNMS: the standard version with increasing delay (s-DNMS), a version with lengthened lists of objects (l-DNMS), which has been used routinely by Mishkin and colleagues (Meunier et al., 1993), and a new version with increasing delays interrupted with distractors (d-DNMS).

For s-DNMS, the delays were sequentially increased from the initial 10 $\mathrm{sec}$ to $30,60,120$, and $600 \mathrm{sec}$. The animals received five consecutive 20 trial daily sessions (100 trials) for each delay shorter than $600 \mathrm{sec}$ and 10 consecutive 5 trial daily sessions ( 50 trials) at the $600 \mathrm{sec}$ delay. Intertrial intervals lasted $30 \mathrm{sec}$ in all conditions.

For l-DNMS, the number of objects presented during the sample phase was increased from the initial 1 object to 3,5 , and 10 objects. During the sample phase, the objects composing the list were presented sequentially, separated by 20 sec intervals. After the last 20 sec interval, each sample object was paired with a novel one, and the pairs were presented one at a time, also at $20 \mathrm{sec}$ intervals, with the familiar objects appearing in the same order as in the sample phase. The monkeys received five consecutive 30 trial daily sessions (150 trials) for each list length.

For d-DNMS, monkeys were tested first at the $10 \mathrm{sec}$ delay used during DNMS learning and then at the longer delays of 30,60, 120, and $600 \mathrm{sec}$ used during s-DNMS. Daily sessions on all d-DNMS conditions but one (see below) comprised 10 trials with distraction intermixed pseudorandomly with 20 standard trials without distraction. The distraction was always introduced at the beginning of the delay period. Three different types of distraction were selected. For the $10 \mathrm{sec}$ delay condition, the monkey's compartment was illuminated for $3 \mathrm{sec}$ during distraction trials (distraction type 1 or light). During the subsequent 30-600 sec conditions, the monkey performed a motor task during distraction trials, which consisted in removing a lifesaver (donut-shape fruit) candy from a twisted metal wire. The number of bends in the metal wire was increased to maintain the animal's engagement in the motor task for $\sim 10 \mathrm{sec}$ (distraction type 2 or motor task). Finally, an additional $600 \mathrm{sec}$ delay condition was administered and consisted of removing the animal from the WGTA at the end of the sample presentation, transporting it to its housing room, and then returning it to the WGTA at the end of the 600 sec delay period to complete the trial (distraction type 3 or context change). For distraction types 1 and 2 (except delays of $600 \mathrm{sec}$ see below), the monkeys received a total of 150 trials, 50 with distraction and 100 standard ones. For the 600- sec delay conditions of d-DNMS types 2 and 3, daily sessions were downsized to five trials per session and were performed over 10 consecutive days. For type 2 condition, the motor task intervened on only two of the five daily trials, and, thus, among the total 50 trials given, 20 were distraction trials and 30 were standard ones. For type 3 condition, removal of the animal from the WGTA occurred on every daily trial, thus all 50 trials were trials with distraction.

Behavioral data analysis. Multifactorial ANOVAs were used with groups (four) for between-subjects comparisons and variables (with repeated measures when appropriate) for within-subjects comparisons. For all variables with repeated measures, degrees of freedom were corrected with Huynh-Feldt epsilon. Additionally, planned comparisons were performed separately between the control group and each experimental group, using a one-sided Dunnett's test, and between each experimental group using a Tukey test. One-way ANOVAs or paired $t$ tests were used to evaluate within-group evolution of performance across testing conditions. A one-sided $t$ test was used to compare performance to chance level. Kruskal-Wallis and Mann-Whitney $U$ tests were used for analyses of all nonparametric measures. Finally, behavioral parameters measured on each task were correlated with the percentage of damage (intended or unintended) to each brain region using Pearson correlations.

\section{Histology}

At the end of the behavioral experiments, the operated animals were sedated, given a lethal dose of sodium pentobarbital, and perfused intracardially with $0.9 \%$ saline, followed by $4.0 \%$ paraformaldehyde. The brain was photographed and cut frozen at $50 \mu \mathrm{m}$ in the coronal plane. Every fifth section was mounted and stained with thionin to visualize cell bodies. In addition, for cases $\mathrm{H}-1$ and $\mathrm{H}-2$ and all cases in groups PRh and $\mathrm{TH} / \mathrm{TF}$, every 30 th section was impregnated with silver to identify fibers.

To reconstruct the lesions, drawings of coronal sections at $1 \mathrm{~mm}$ intervals through a normal brain were used (Nemanic et al., 2002). The volume of each neural region of the intact rhesus brain (i.e., the hippocampal subfields, subicular complex, amygdaloid nuclei, entorhinal and PRh cortices, and cortical areas TE, TEO, TH, TF, TG, and V2) was calculated by summing the area across all sections and multiplying this number by the distance between the sections (i.e., $1 \mathrm{~mm}$ ).

For each operated monkey, histological slides were matched to the coronal digitized images of the normal rhesus brain. Two independent observers estimated the extent of damage microscopically and plotted the damaged area onto the corresponding images of the intact brain. Using the Image program (Scion, Frederick, MD), the damaged area of each region of interest was measured on each coronal image, and the percentage of damage to each region was calculated. For all cortical lesions, the histological damage was compared with the postsurgical T1-weighted MRI, for general confrontation of the results from the two techniques, and also to determine, in the case of white matter transection, whether it occurred during surgery or resulted from histological processing.

\section{Results}

\section{Lesion extent}

In all operated groups, lesion extent revealed by postmortem histology was remarkably similar to the damage visualized by noninvasive MRI. This further demonstrates the reliability of neuroimaging for lesion evaluation in monkeys (Málková et al., 2001b; Nemanic et al., 2002). The percentage of damage to medial temporal structures is detailed in Tables 1-3 for each operated animal, and the estimated lesion extent for each case is illustrated in Figures 1, 2, 4, 5, 7 , and 8 . In addition, photomicrographs of the actual lesion are provided for cases H-1 (Fig. 3), PRh-4 (see Fig. 6), and TH/TF-3 (see Fig. 8). The following paragraphs will, therefore, be limited to a brief overview of damage in each group.

\section{Hippocampal lesions}

Damage to the hippocampal formation was incomplete in all cases, ranging from 20 to $64 \%$ (Table 1), and varied, in addition, across hemispheres, among hippocampal fields and along the AP plane (Figs. 1-3). Lesions were bilaterally symmetrical in two 
Table 1. Intended damage in group H

\begin{tabular}{|c|c|c|c|c|c|c|c|c|c|c|c|c|}
\hline & \multicolumn{4}{|l|}{ CA1 } & \multicolumn{4}{|l|}{ CA2 } & \multicolumn{4}{|l|}{ CA3 } \\
\hline & $\mathrm{L}$ & $\mathrm{R}$ & Avg & W & L & $\mathrm{R}$ & Avg & W & $\mathrm{L}$ & $\mathrm{R}$ & Avg & W \\
\hline \multicolumn{13}{|c|}{ Subjects } \\
\hline $\mathrm{H}-1$ & 82.9 & 44.3 & 63.6 & 36.7 & 55.5 & 25.9 & 40.7 & 14.4 & 64.5 & 52.6 & 58.5 & 33.9 \\
\hline $\mathrm{H}-2$ & 21.1 & 40.2 & 30.7 & 8.5 & 24.5 & 46.4 & 35.4 & 11.4 & 35.1 & 90.7 & 62.9 & 31.8 \\
\hline $\mathrm{H}-4$ & 31.6 & 20.3 & 26 & 6.4 & 36.5 & 9.9 & 23.2 & 3.6 & 14.3 & 2.5 & 8.4 & 0.35 \\
\hline $\mathrm{H}-5$ & 83.6 & 5.9 & 44.7 & 4.9 & 82.5 & 9.2 & 45.8 & 7.6 & 64.9 & 14.8 & 39.9 & 9.6 \\
\hline \multirow[t]{3}{*}{$x$} & 54.8 & 27.7 & 41.3 & 14.1 & 49.8 & 22.9 & 36.3 & 9.25 & 44.7 & 40.2 & 42.4 & 18.9 \\
\hline & \multicolumn{4}{|c|}{ Dentate gyrus } & \multicolumn{4}{|c|}{ Subicular complex } & \multicolumn{4}{|l|}{ Total } \\
\hline & $\mathrm{L}$ & $\mathrm{R}$ & Avg & W & L & $\mathrm{R}$ & Avg & W & $\mathrm{L}$ & $\mathrm{R}$ & Avg & W \\
\hline \multicolumn{13}{|l|}{ Subjects } \\
\hline $\mathrm{H}-1$ & 71.9 & 64.3 & 68.1 & 46.3 & 74 & 59.5 & 66.7 & 44 & 72.5 & 54.7 & 63.6 & 39.6 \\
\hline $\mathrm{H}-2$ & 13.3 & 74.1 & 43.7 & 9.9 & 1.6 & 66.8 & 34.2 & 1.1 & 16.8 & 66.5 & 41.7 & 11.2 \\
\hline $\mathrm{H}-4$ & 21.3 & 15.1 & 18.7 & 3.4 & 14.9 & 41.6 & 28.2 & 6.2 & 22.1 & 18.7 & 20.4 & 4.1 \\
\hline $\mathrm{H}-5$ & 44.3 & 11.8 & 28 & 5.2 & 63.4 & 6.3 & 34.9 & 4 & 62.7 & 9.8 & 36.4 & 6.3 \\
\hline$X$ & 37.8 & 41.3 & 39.6 & 16.2 & 38.5 & 43.6 & 41 & 13.8 & 43.5 & 37.4 & 40.5 & 15.4 \\
\hline
\end{tabular}

Data are the estimated percentage of normal volume. CA1-3, Ammon fields; $L$, percentage of damage to the left hemisphere; $R$, percentage of damage to the right hemisphere; Avg, average of $L$ and $R$. $W=(L \times R) / 100[$ weighted index as defined by Hodos and Bobko (1984)].

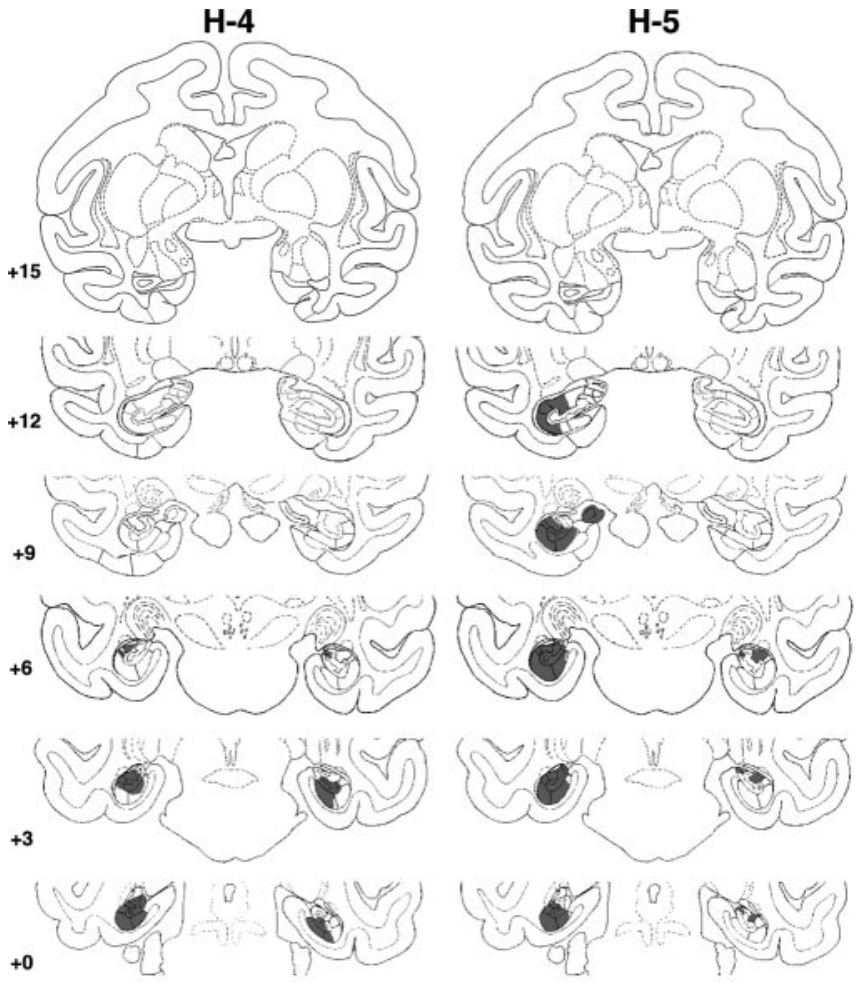

Figure 2. Coronal sections through the actual damage in cases $\mathrm{H}-4$ and $\mathrm{H}-5$ with neurotoxic lesions of the hippocampal formation, shown in black. The numerals on the left of each coronal section of the intended lesions indicate the distance in millimeters from the interaural plane. The asterisks point to unintended damage to adjacent structures.

cases. In one of them, $\mathrm{H}-1$, cell loss was extensive, encompassing all but the rostralmost $2 \mathrm{~mm}$ of the hippocampal formations (Fig. 1) (levels +12 and +15$)$, whereas in the other, $\mathrm{H}-4$, cell loss was confined to the caudalmost portion of the hippocampal formation (Fig. 2) (levels $+6,+3$, and 0 ). In the remaining two cases, $\mathrm{H}-2$ and $\mathrm{H}-5$, cell loss was extensive $(>60 \%)$ on one side but only moderate on the other $(<20 \%)$. Microscopic inspection of the silver impregnated sections in cases $\mathrm{H}-1$ and $\mathrm{H}-2$ revealed no detectable damage to the fibers coursing around the hippocampal formation, indicating that the concentration of ibotenic acid used to produce the lesions was sufficient to destroy cell bodies while leaving fibers mostly intact. In fact, this was true even for case $\mathrm{H}-1$, in which the ibotenic acid targeted to the body of the hippocampus diffused across the white matter ventrally and destroyed cells in areas TH and TF (Nemanic et al., 2002) (Fig. 3). Finally, unintended damage to adjacent cortical areas was minimal and limited to areas $\mathrm{TH}$ and $\mathrm{TF}$ in two cases. Thus, case $\mathrm{H}-1$ had bilateral damage to both areas $\mathrm{TH}$ (1.3\% on the left and $54.3 \%$ on the right) and TF (18\% on the left and $5.2 \%$ on the right), whereas case $\mathrm{H}-2$ had unilateral damage to area $\mathrm{TH}$ on the left only $(4.8 \%)$.

\section{PRh lesions}

Removals of the PRh cortex were bilaterally extensive in all cases, ranging from 83 to $91 \%$ (Table 2; Figs. 4-6). As for extra damage medially, encroachment onto entorhinal cortex was moderate $(<20 \%)$ in all cases. Rostrally, the lesions involved the medial part of polar area TG in cases PRh-1, -3 , and -5 bilaterally, and in case PRh-2, unilaterally. Inadvertent damage to visual area TE was minor $(<10 \%)$ in cases PRh-2, -3 and -4 but moderate $(>30 \%)$ in cases PRh-1 and PRh-5. In the latter cases, this damage extended further laterally to include both banks of the superior temporal sulcus, in the right hemisphere for case PRh-1 (Fig. 4) (levels $+18,+15$, and +12$)$ and in the left hemisphere for case PRh-5 (Fig. 5) (levels +18). All cases sustained only minor damage $(<10 \%)$ to parahippocampal areas TH and TF. The hippocampal formation was left intact. In addition, inspection of the silver impregnated sections indicate that substantial damage to the white matter just beneath the cortical lesion was found in cases PRh-1 and PRh-5, although in the other cases mild inadvertent damage to the white matter adjacent to the actual aspiration removal could have occurred but cannot be appreciated from the histological material.

\section{Areas TH/TF lesions}

Removal of areas TH/TF (Figs. 7, 8; Table 3) were bilaterally extensive in cases TH/TF-2 and TH/TF-3, reaching 90 and $88 \%$, respectively. In the remaining case, the removal was also bilaterally symmetrical but was less complete $(66 \%)$ because of sparing of the caudalmost portion of the parahippocampal areas (Fig. 7) (level -3). Except for 35\% damage to the left subicular complex in case TH/TF-2 (Fig. 7) (levels +3 and +6 ), inadvertent damage to temporal cortical areas remained minimal $(<10 \%)$ in this group. Note that damage to the fibers just below areas TH/TF visible on histological sections (Fig. 8), was not present on the 


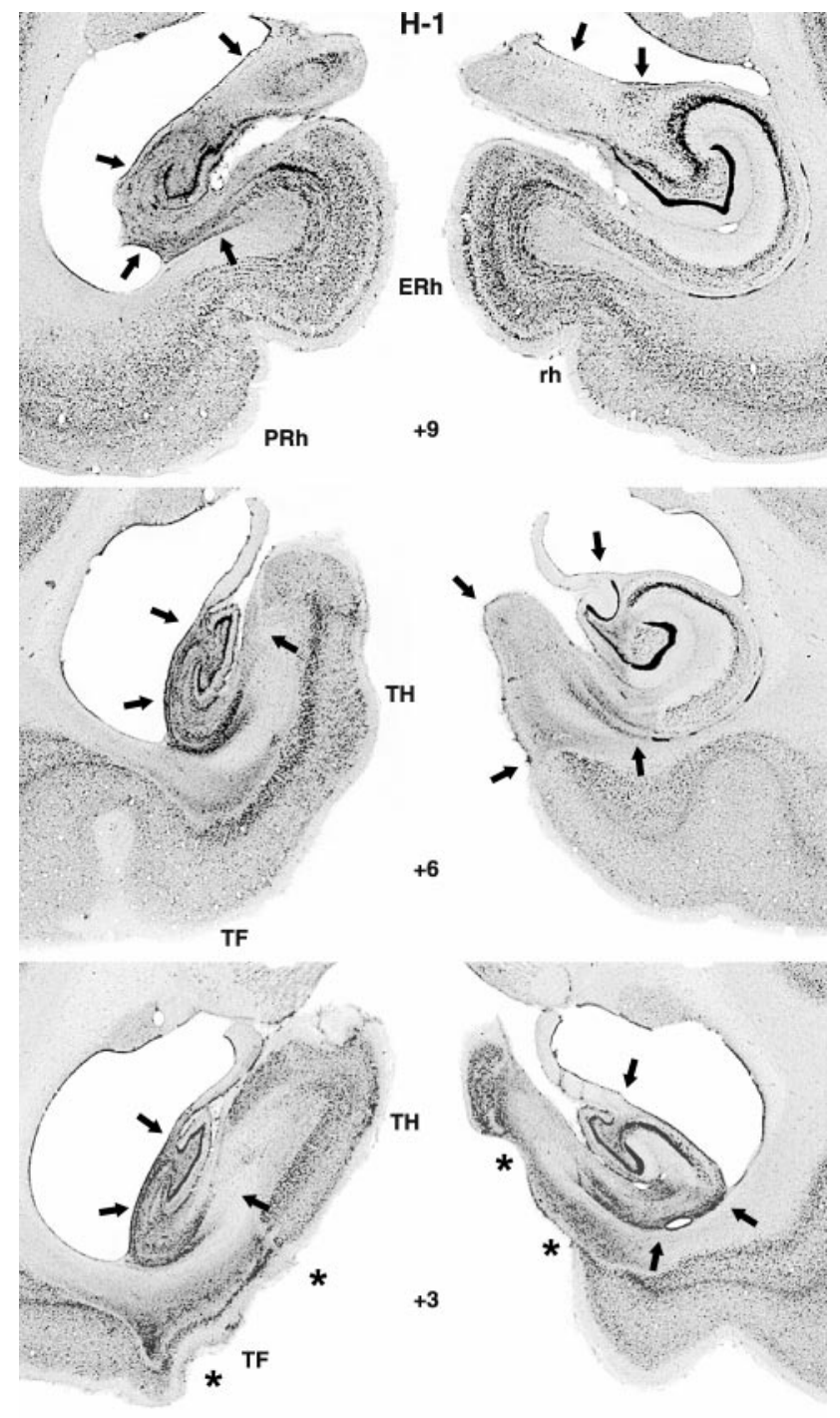

Figure 3. Photomicrographs of thionine-stained coronal sections from a monkey with a hippocampal lesion (case H-1). The arrows indicate sites of cell death. Notice that the lesion extended through the entire left hippocampal formation, whereas it spared the lateralmost portion of the right hippocampal formation. The asterisks point to bilateral unintended damage to areas TH and TF (see level +3). ERh, Entorhinal cortex; rh, rhinal sulcus; TH and TF, cytoarchitectonic fields described by von Bonin and Bailey (1947).

T1-weighed MRI in any of the three cases and, hence, likely occurred during histological processing of brain tissue.

\section{Visual paired comparison}

Familiarization time and total retention time during retention tests did not vary across delay nor did they differ among groups [familiarization time (seconds): 1.45, 1.11, 1.16, and 1.39; and total retention time (seconds): 4.31. 4.25, 4.40 and 4.14; averaged across delays for groups $\mathrm{N}, \mathrm{H}, \mathrm{PRh}$, and $\mathrm{TH} / \mathrm{TF}$, respectively]. These results indicated that operated animals did not suffer from attentional/motivational problems (i.e., a general lack of interest in looking at the pictures). For saccade frequency, ANOVAs similarly failed to yield any significant delay or group effect [average across delays: 1.69, 2.20, 1.94 and 2.87 saccades for groups $\mathrm{N}, \mathrm{H}$, $\mathrm{PRh}$, and TH/TF, respectively]. Yet, monkeys in group TH/TF tended to make more saccades than controls [Dunnett's test; $p=$ 0.034], and this propensity seemed positively correlated with the amount of parahippocampal damage they had sustained ( $r=$ $0.96 ; p<0.01)$. This raises the possibility that inappropriate visual exploration (Ringo et al., 1994; Sobotka et al., 1997) may have interfered with VPC performance in group TH/TF (especially at delays $\geq 30 \mathrm{sec}$; see below).

The percentage of looking time at novel objects (Fig. 9) did differ among groups $\left(F_{(3,11)}=28.17 ; p<0.0001\right)$, and group differences varied across delays (delay: $F_{(\text {HUYNH-FELDT })(4,44)}=$ $4.57 ; p<0.004$; group $\times$ delay interaction: $F_{(\text {HUYNH-FELDT })(12,44)}$ $=1.92 ; p<0.05)$. Indeed, whereas group $\mathrm{N}$ showed a stable $65 \%$ novelty preference and performed well above the $50 \%$ chance level at all delays (all $p<0.0001$ ), all operated groups presented a delay-dependent impairment that, once it emerged at a given delay, persisted through longer delays.

Group $\mathrm{H}$ switched from normal novelty preference scores for delays $<60 \sec$ (all $p<0.03$, relative to chance) to complete loss of novelty preference for delays $\geq 60 \mathrm{sec}$. Their scores, which did not differ from chance at the 60 and $120 \mathrm{sec}$ delays, were also lower than those of controls (Dunnett's test; both $p<0.002$ ). The same pattern was observed in group TH/TF, except that, in this group, a delay as short as $30 \mathrm{sec}$ was sufficient to suppress novelty preference (relative to chance; all $p<0.01$ at 10 and $20 \mathrm{sec}$ and $p=\mathrm{NS}$ at $30-120 \mathrm{sec}$ ). Novelty preference scores in group TH/TF differed from those of group $N$ at delays of $\geq 30 \mathrm{sec}$ (Dunnett's test; $p=0.07$ at $30 \mathrm{sec}$ and $p<0.001$ at 60 and $120 \mathrm{sec}$ ). For group $\mathrm{PRh}$, the pattern of impairment was somewhat different. First, this group showed spared novelty preference only during additional testing performed with $1 \mathrm{sec}$ delays $(p<0.02$, relative to chance; $p=$ NS compared with normal animals' performance at $10 \mathrm{sec}$ ). Second, the impairment in group PRh emerged more gradually than in the other operated groups. Namely, novelty preference was first diminished (i.e., poorer than in controls) (Dunnett's test; $p<0.05)$ but still above chance $(p<0.02)$ at 10 sec delays, before being virtually abolished for all delays $>20 \mathrm{sec}$ (all $p=\mathrm{NS}$, except at $60 \mathrm{sec}, p<0.02$; relative to chance and Dunnett's test; all $p<0.05$ compared with controls).

\section{Summary}

All three medial temporal lesions abolished preference to novelty, although this deficit occurred at different delays in each operated group. This deficit occurred for delays $\geq 20 \mathrm{sec}$ after PRh lesions, delays $\geq 30 \mathrm{sec}$ after TH/TF lesions, and delays $\geq 60 \mathrm{sec}$ after $\mathrm{H}$ lesions. PRh lesions, nevertheless, stood apart from $\mathrm{H}$ and $\mathrm{TH} / \mathrm{TF}$ lesions, in that only with minimal $1 \mathrm{sec}$ delays did they spare novelty preference.

\section{Object DNMS}

\section{Acquisition}

The number of trials and errors required to learn the nonmatching rule with $10 \mathrm{sec}$ delays between sample and choice differed among groups (Kruskal-Wallis test; $p<0.02$ and $p<0.01$, respectively). Group $\mathrm{H}$ reached learning criterion as readily as group N (mean: 123 and 125 trials, respectively). In contrast, groups PRh (mean, 961 trials) and TH/TF (mean, 524 trials) were retarded, thereby contrasting with both groups $\mathrm{H}$ and $\mathrm{N}$ (all $p<$ 0.05 for both trials and errors). Groups PRh and TH/TF did not significantly differ from each other. However, cases PRh-2 and $\mathrm{PRh}-3$ required $>1000$ trials to reach criterion, and $\mathrm{PRh}-1$ failed to quite reach it after 1500 trials. Thus, these three cases were more drastically retarded than any of the TH/TF cases.

\section{s-DNMS and l-DNMS}

Performance scores obtained on DNMS with increasing delays and lengthened lists are depicted for each group in Figure 10. For 

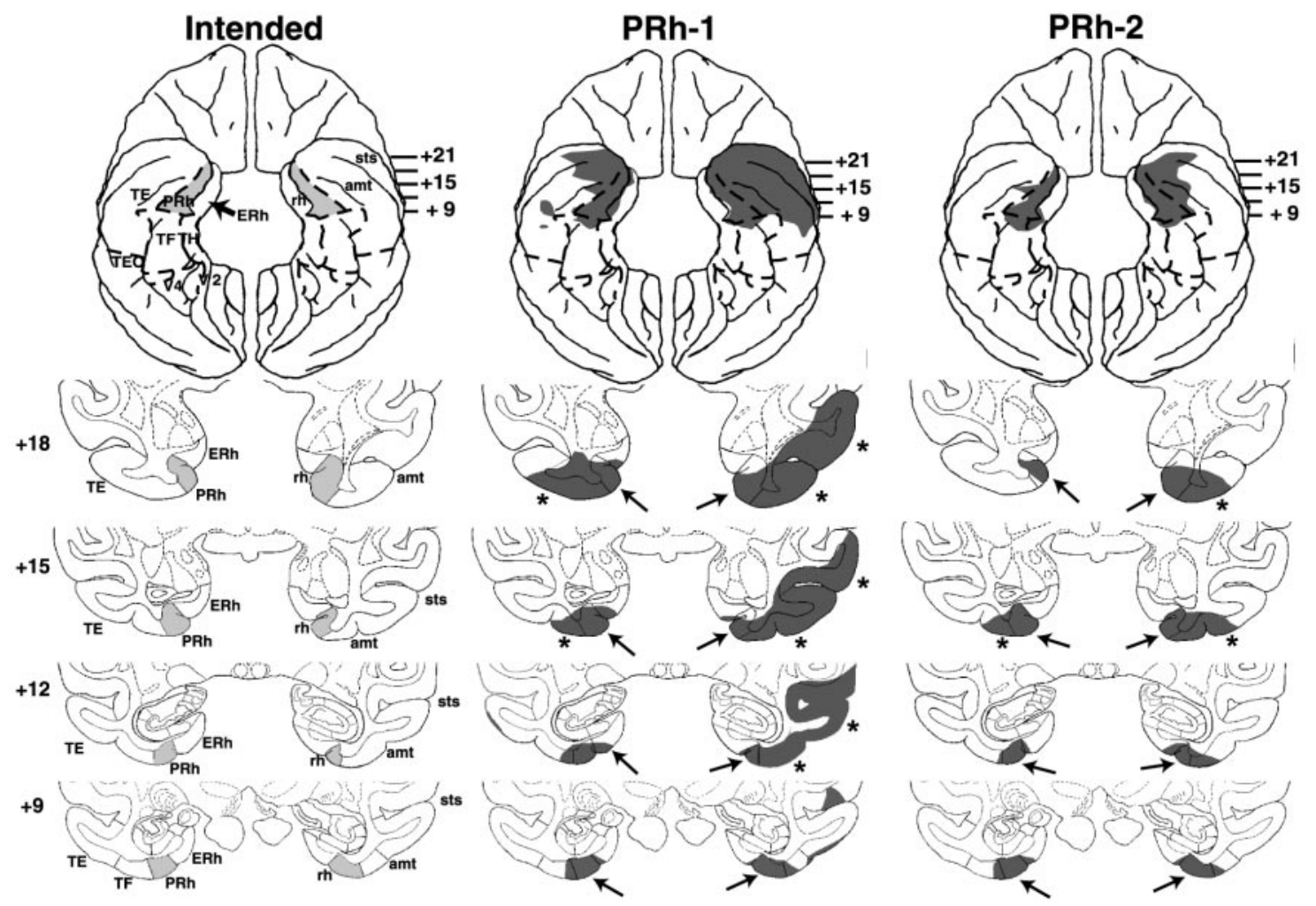

Figure 4. Coronal sections through the PRh cortex, depicting the intended damage (left), shown in gray, and actual damage in cases PRh-1 and PRh-2 with aspiration lesions of the PRh cortex, shown in black. The numerals on the left of each coronal section of the intended lesions indicate the distance in millimeters from the interaural plane. The asterisks point to unintended damage to adjacent structures. amt, Anterior middle temporal sulcus; ERh, entorhinal cortex; pmt, posterior middle temporal sulcus; rh, rhinal sulcus; ot, occipitotemporal sulcus; sts, superior temporal sulcus; TE, TE0, TH and TF, cytoarchitectonic fields described by von Bonin and Bailey (1947).

Table 2. Intended and unintended damage in group PRh

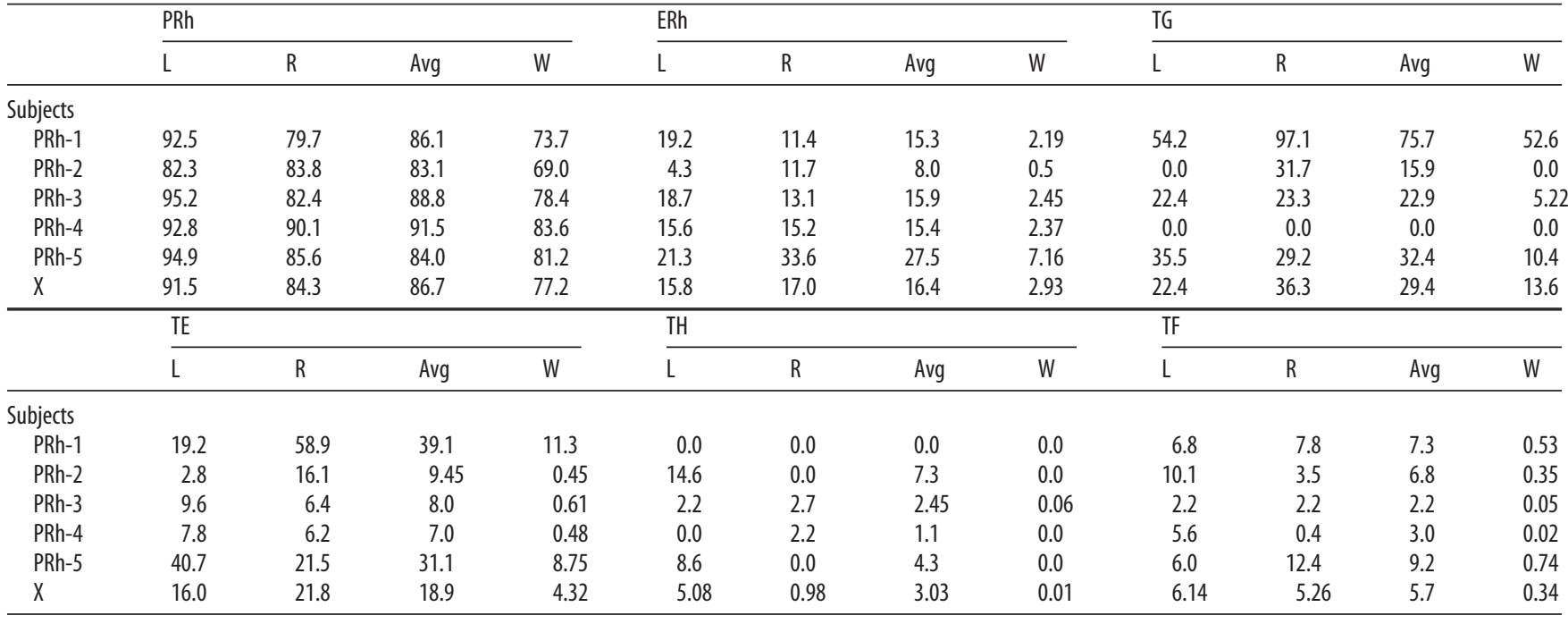

ERh, Entorhinal cortex; TH and TF, parahippocampal areas as defined by von Bonin and Bailey (1947). For other abbreviations, see Table 1.

s-DNMS, the two main factors and their interaction were significant (group: $F_{(3,11)}=10.87, p<0.001$; delay: $F_{(\text {HUYNH- }}$ FELDT $(3,29)=14.81, p<0.0001 ;$ group $\times$ delay: $F_{(\text {HUYNH }}$ FELDT $(8,29)=3.08, p<0.02)$. Post hoc analyses for each delay revealed no significant difference between monkeys in groups $\mathrm{H}$ and TH/TF and those in group $\mathrm{N}$, although cases $\mathrm{H}-1$ (which sustained the most bilaterally extensive cell loss) and $\mathrm{H}-2$, as well as all three TH/TF cases, performed somewhat more poorly than controls at $600 \mathrm{sec}$. In contrast, group PRh was significantly impaired relative to groups $\mathrm{N}$ (Dunnett's test; all $p<0.02$ ) and $\mathrm{H}$ (Tukey test; all $p<0.03$ ) at all delays and marginally impaired relative to group $\mathrm{TH} / \mathrm{TF}$ at delays of $60-600 \mathrm{sec}$ (Tukey test; all $p<0.09$ ). Withingroup ANOVAs confirmed that group PRh $\left(F_{(\text {HUYNH-FELDT })(3,12)}=\right.$ $14.44 ; p<0.001)$ and, to a lesser extent, group TH/TF $\left(F_{(\mathrm{HUYNH}-}\right.$ FELDT) $(3,6)=9.53 ; p=0.054)$ showed a delay-dependent decrease in performance, which was absent in both groups $\mathrm{H}$ and $\mathrm{N}$.

For l-DNMS, both main effects were significant (group: $F_{(3,11)}=$ 10.76, $p<0.001$; list length: $F_{(\text {HUYNH-FELDT })(2,22)}=10.20, p<$ 

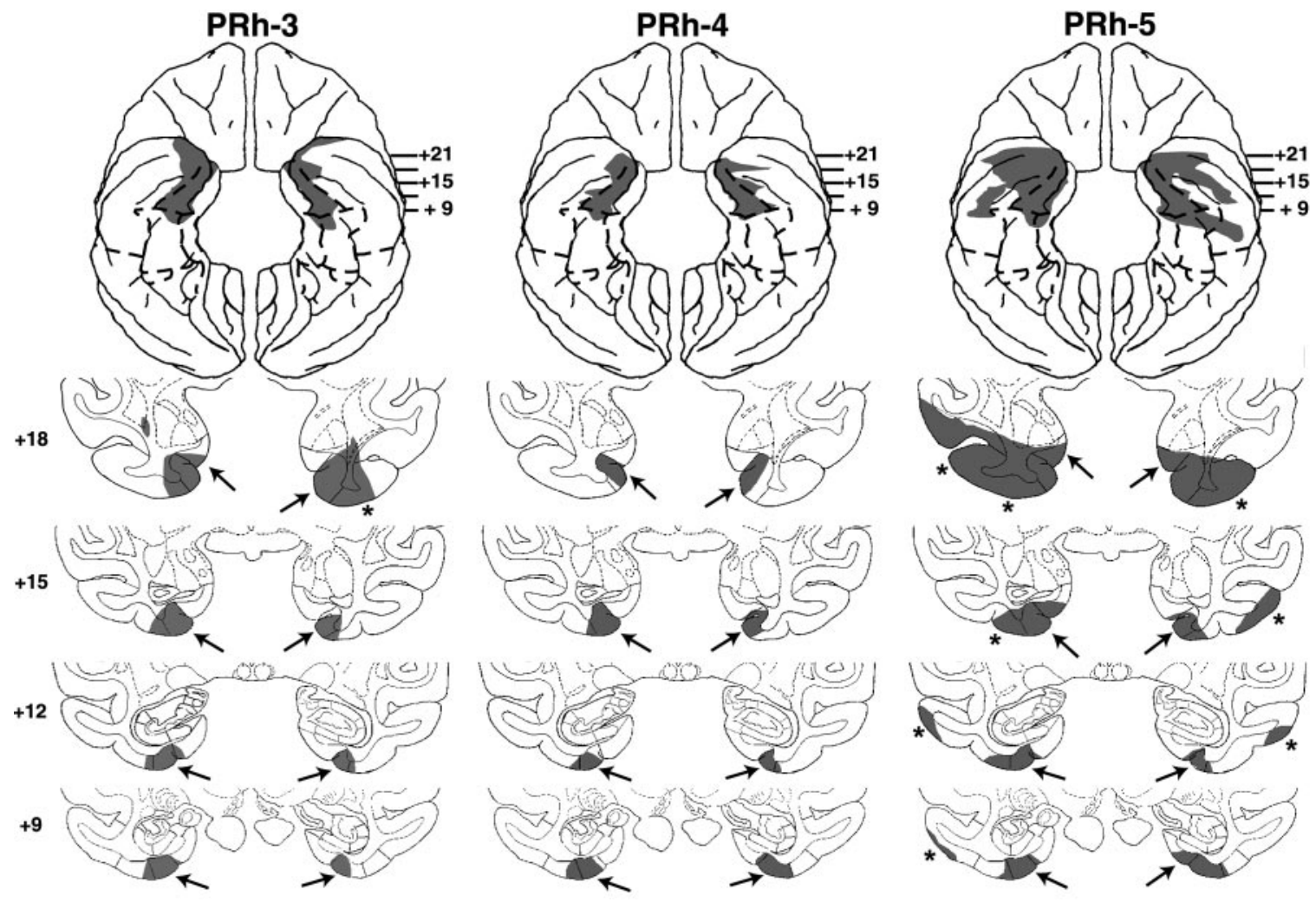

Figure 5. Coronal sections through the actual damage in cases PRh-3, -4 , and -5 with aspiration lesions of the PRh cortex, shown in black. The numerals on the left of each coronal section of the intended lesions indicate the distance in millimeters from the interaural plane. The asterisks point to unintended damage to adjacent structures.

0.001). Post hoc analysis revealed that only group PRh was impaired on l-DNMS, thereby differing from both group N (Dunnett's test; all $p<0.015$ ) and groups $\mathrm{H}$ and TH/TF (Tukey test; all $p<0.05$ ) for each list. This time, no hint of a deficit was detectable in the two latter groups (even case $\mathrm{H}-1$, which sustained the largest lesion and scored poorly at $600 \mathrm{sec}$ delays, performed normally on all l-DNMS conditions). Within-group ANOVAs indicated that group PRh was the sole group whose performance significantly worsened with increasing numbers of objects to be remembered $\left(F_{(\text {HUYNH-FELDT })(2,8)}=\right.$ $5.71 ; p<0.03$ ).

The most noteworthy correlations observed between extent of damage and performance over s-DNMS or 1-DNMS are the following. For group $\mathrm{H}$, greater combined damage (left and right) to the hippocampal formation correlated positively with recognition loss at the longest delays $(r=0.89, p<0.02$ at $60 \mathrm{sec} ; r=$ $0.99, p<0.001$ at $120 \mathrm{sec} ; r=0.95, p<0.004$ at $600 \mathrm{sec})$. For group $\mathrm{PRh}$, unintended damage to area TE and entorhinal cortex correlated positively with recognition loss at the $10 \mathrm{sec}$ delay $(r=$ $0.8 ; p<0.05)$ and list length of 10 objects $(r=-0.89 ; p<0.02)$. Finally, for group TH/TF, damage to TH/TF correlated positively with recognition loss at the 30 and 60 sec delays $(r=0.90 ; p<0.04)$.

\section{d-DNMS}

Group averages on the standard and distraction trials of each d-DNMS type are depicted in Figure 11. For distraction type 1 (10 sec delays with an intervening light), both main effects and their interaction were significant (group: $F_{(3,11)}=8.84, p<0.003$; trial type: $F_{(1,11)}=3.61, p<0.08$; group $\times$ trial type: $F_{(\mathrm{HUYNH}-}$ FELDT $(3,11)=8.01, p<0.004)$. Pairwise comparisons showed that, on the distraction trials, group PRh performed more poorly than each of the other three groups (Dunnett's and Tukey tests; all $p<0.01$ ), which did not differ from each other. Within-group analyses confirmed that group PRh was the sole group whose performance was significantly hindered by the mere illumination of the monkeys' WGTA compartment for $3 \mathrm{sec}$ at the beginning of a $10 \mathrm{sec}$ retention period [paired $t$ test: $t(4)=3.80, p<0.02$ ].

For distraction type $2(30-600 \mathrm{sec}$ delays with an intervening motor task), performance scores differed significantly between groups $\left(F_{(3,11)}=21.23 ; p<0.0001\right)$, delays $\left(F_{(\text {HUYNH-FELDT })(3,11)}\right.$ $=7.13 ; p<0.008)$, and trial types $\left(F_{(1,11)}=8.69 ; p<0.02\right)$, but none of the interactions was significant. On distraction trials, group $\mathrm{PRh}$ again exhibited the lowest scores, systematically differing from all other groups (all $p<0.01$ ), except from group $\mathrm{H}$ at $600 \mathrm{sec}$. Group TH/TF scores fell within the normal range on all distraction trials. In group $\mathrm{H}$, although no reliable difference was found relative to controls, all cases but $\mathrm{H}-4$ (which sustained the smallest lesion) performed somewhat more poorly than controls on $600 \mathrm{sec}$ trials with distraction. Within-group analyses indicated that group PRh was the sole group significantly affected by the intervening motor task. This vulnerability to distraction was evident at 30 and $60 \mathrm{sec}$ delays [paired $t$ test: $t(4)=5.9, p<0.005$; and $t(4)=4.2, p<0.02$, respectively], although concealed by a floor effect at 120 and $600 \mathrm{sec}$ delays (PRh scores being by then too close to chance level to accommodate any additional decrease).

For distraction type 3 (600 sec delays with a context change), the effect of groups was significant (group: $F_{(3,11)}=28.38, p<$ 0.0001 ), and comparisons between trial type failed just short of significance $\left(F_{(1,11)}=3.89 ; p=0.074\right)$. This time, group H performed significantly more poorly than controls on distraction trials (Dunnett's test; $p<0.01$ ), without reaching, however, the degree of impairment of group PRh, the scores of which re- 

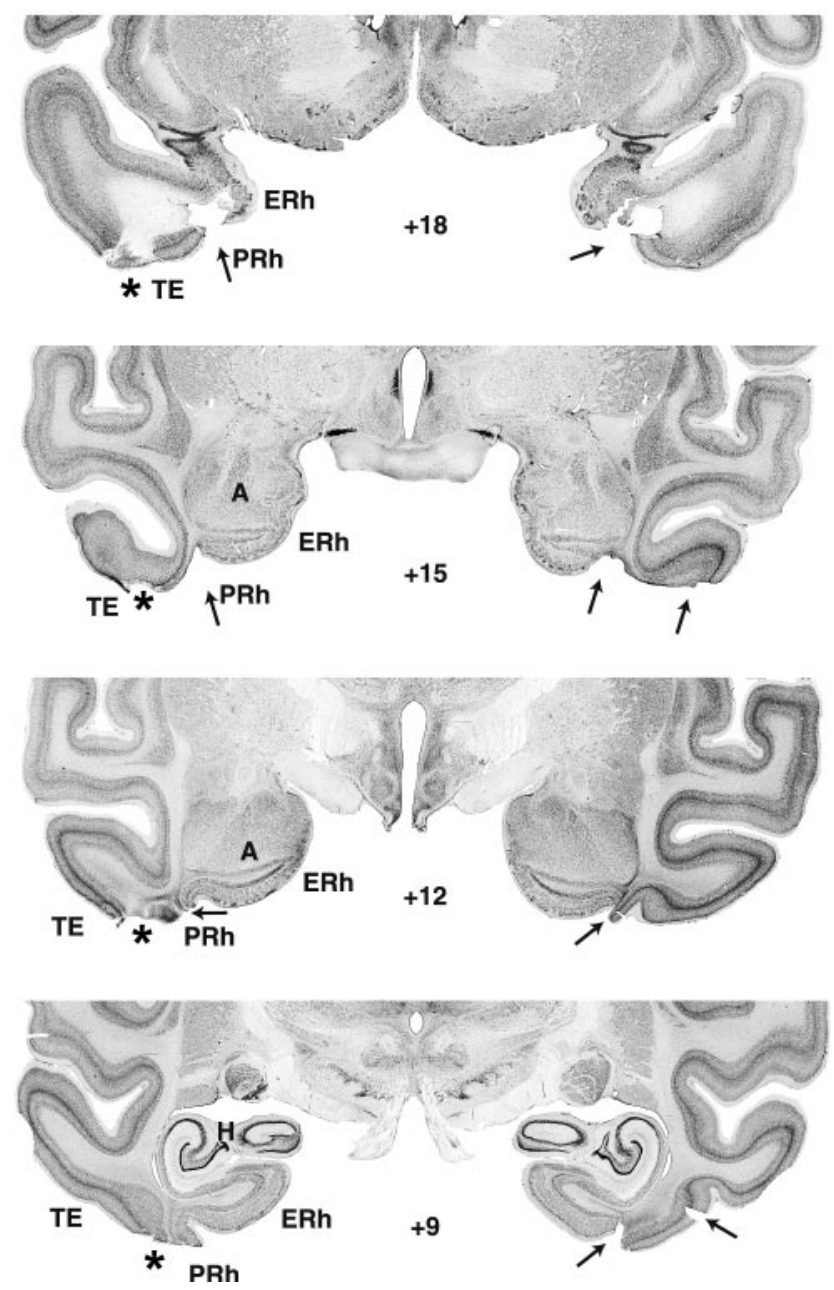

Figure 6. Photomicrographs of thionin-stained coronal sections from a monkey with a PRh lesion (case PRh-4). ERh, Entorhinal cortex; TE, cytoarchitectonic fields described by von Bonin and Bailey(1947).

mained lower than those of each of the other three groups (Dunnett's and Tukey tests; all $p<0.001)$. Within-group analyses confirmed that only group $\mathrm{H}$ was significantly $(p<0.05)$ affected by removal from the WGTA during the delay between sample and choice distraction (any distraction effect in group PRh being again limited by a floor effect). Indeed, even case $\mathrm{H}-4$, which sustained the smallest lesion and displayed excellent scores on all other DNMS versions and conditions, did show a 19\% drop in performance on $600 \mathrm{sec}$ trials with an intervening context change relative to standard trials at the same delay. Correlation analyses failed to reveal any clear-cut link between damage extent and d-DNMS scores.

Test-retest effect on standard trials

In Table 4, scores on standard trials obtained during d-DNMS with 30-600 sec delays (test 2) are compared with those observed previously $(\sim 4$ weeks earlier) during s-DNMS with the same delays (test 1). A three-factor ANOVA indicated that performance differed across groups $\left(F_{(3,11)}=16.7 ; p<0.0001\right)$, delays $\left(F_{(\text {HUYNH-FELDT })(3,33)}=15.5 ; p<0.0001\right)$, and times of DNMS testing $\left(F_{(1,11)}=34.1 ; p<0.0001\right)$, with significant group $\times$ time of testing $\left(F_{(3,11)}=3.6 ; p=0.05\right)$ and delay $\times$ time of testing $\left(F_{(\text {HUYNH-FELDT })(3,29)}=2.88 ; p=0.05\right)$ interactions. No deterioration of performance occurred in test 2 relative to test 1 , indicating that none of the groups was adversely affected by the dis- traction trials co-occurring with test 2 . The statistical differences listed above reflected, in contrast, an improvement in performance in test 2, which was most clear-cut in groups $\mathrm{H}$ and $\mathrm{TH} /$ $\mathrm{TF}$, as detailed in Table $4\left(F_{(1,3)}=10.03, p<0.05 ; F_{(1,2)}=29.64\right.$, $p<0.03$, respectively). In particular, the hint of deficit present in $\mathrm{TH} / \mathrm{TF}$ cases at $600 \mathrm{sec}$ delays in test 1 vanished in test 2 . The same holds true for case $\mathrm{H}-1$ (which sustained the most extensive bilateral hippocampal damage).

\section{Summary}

Thus, as for VPC, the effects of the three medial temporal lesions on DNMS differed. PRh lesions markedly retarded acquisition of the nonmatching rule with $10 \mathrm{sec}$ delays and subsequently yielded a deficit that was equally exacerbated by increasing delays, lengthened lists of object to be remembered, or distraction of any kind. In comparison, the consequences of $\mathrm{TH} / \mathrm{TF}$ and $\mathrm{H}$ lesions on DNMS seemed minimal. TH/TF lesions did retard DNMS learning (albeit not as drastically as PRh lesions), but once the nonmatching rule was mastered, performance on all DNMS versions and conditions was left virtually unaltered. Only a hint of deficit was detected with $600 \mathrm{sec}$ undistracted delays, which vanished on subsequent retest at the same delay, whether performed with or without intervening distraction (a motor task or context change). Unlike TH/TF lesions, $\mathrm{H}$ lesions had no effects on DNMS learning. In addition, the hint of deficit they triggered on $600 \mathrm{sec}$ undistracted delays, although alleviated by subsequent retest on the same condition, could be reinstated by an intervening distraction. This effect was most clear-cut after a context change lasting for the entire $600 \mathrm{sec}$ period (achieved by transferring the animal from the testing room to its housing room) than by a shortlasting $(10 \mathrm{sec})$ motor task performed at the start of the delay.

\section{Comparisons between VPC versus DNMS performance}

Comparisons of performance on VPC and DNMS in the three operated groups of the present study indicate that similar performance on both tasks occurred only for monkeys with PRh removals, which presented moderate deficits on the easiest conditions that became more severe with increasingly difficult conditions. In contrast, monkeys with $\mathrm{H}$ or TH/TF removals exhibited severe VPC deficits while respectively showing either a moderate deficit selectively occurring on the most difficult DNMS conditions or no DNMS deficit at all. In the case of the present results, the different outcomes of $\mathrm{H}$ and $\mathrm{TH} / \mathrm{TF}$ lesions on the two tasks cannot have simply resulted from variations in lesion extent or behavioral procedures because the same animals were tested on both. Overall, the findings indicate that VPC seems to be more sensitive to damage to the medial temporal structures than DNMS, and, thus, the two tasks cannot be considered as identical, interchangeable recognition memory probes. As a corollary, the different outcomes of the two recognition tasks in the three operated groups might indicate that medial temporal lobe structures contribute differently to recognition. These proposals will be discussed in turn below.

\section{Discussion}

\section{PRh cortex contribution to recognition memory}

PRh lesions equally impaired performance on both recognition tasks, as reported by others (Meunier et al., 1993; Clark et al., 1997; Buffalo et al., 1999; Málková et al., 2001a; Chavoix et al., 2002), although not in the same animals. Monkeys with PRh lesions performed normally on VPC at delays of $10 \mathrm{sec}$ or shorter and were impaired at these same delays in the DNMS task when a distractor intervened, suggesting that this cortical area is involved 

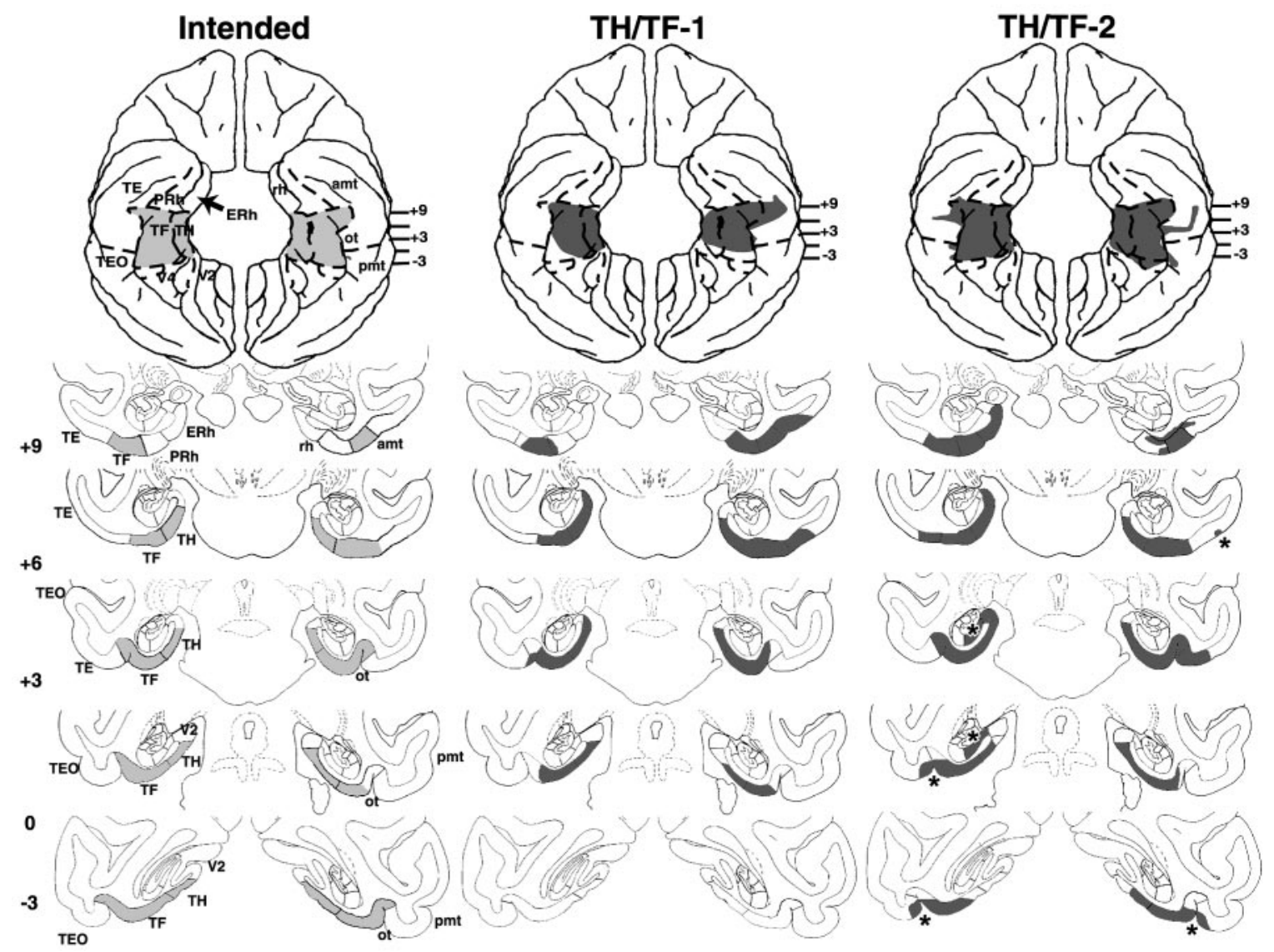

Figure 7. Coronal sections through areas TH and TF, depicting the intended damage (left), shown in gray, and actual damage in cases TH/TF-1 and TH/TF-2 with aspiration lesions of areas TH/TF, shown in black. The numerals on the left of each coronal section of the intended lesions indicate the distance in millimeters from the interaural plane. The asterisks point to unintended damage to adjacent structures. amt, Anterior middle temporal sulcus; ERh, entorhinal cortex; pmt, posterior middle temporal sulcus; rh, rhinal sulcus; ot, occipitotemporal sulcus; sts, superior temporal sulcus; TE, TE0, TH and TF, cytoarchitectonic fields described by von Bonin and Bailey (1947); V2, visual extrastriate cortical areas.

Table 3. Intended damage in group TH/TF

\begin{tabular}{|c|c|c|c|c|c|c|c|c|c|c|c|c|}
\hline \multirow[b]{2}{*}{ Subjects } & \multicolumn{4}{|l|}{ TH } & \multicolumn{4}{|l|}{ TF } & \multicolumn{4}{|l|}{ Total } \\
\hline & $\mathrm{L}$ & $\mathrm{R}$ & Avg & W & $\mathrm{L}$ & $\mathrm{R}$ & Avg & W & $\mathrm{L}$ & $\mathrm{R}$ & Avg & W \\
\hline TH/TF-1 & 68 & 66 & 67 & 45 & 64 & 66 & 65 & 35 & 66.4 & 66 & 66.3 & 40.3 \\
\hline TH/TF-2 & 93 & 85 & 89 & 79 & 93 & 89 & 91 & 83 & 92.9 & 87 & 90.1 & 81 \\
\hline TH/TF-3 & 72 & 96 & 84 & 69 & 92 & 93 & 92 & 85 & 82 & 94 & 88 & 77 \\
\hline$X$ & 78 & 82 & 80 & 65 & 83 & 83 & 83 & 68 & 80.5 & 82.5 & 81.5 & 66.1 \\
\hline
\end{tabular}

For other abbreviations, see Table 1.

in the short-term memory process as already alluded to in the literature (cf. Buckley and Gaffan, 1998; Buffalo et al., 2000; Murray, 2000; Buckley et al., 2001; Murray and Richmond, 2001). This proposal is also consistent with electrophysiological (Riches et al., 1991; Miller et al., 1991; Miller and Desimone, 1994; Xiang and Brown, 1998) and functional mapping (Blaizot et al., 2000; Davachi and Goldman-Rakic, 2001) studies in monkeys, and with molecular activation of $c$-fos in rodents (Zhu et al., 1996; Wan et al., 1999).

\section{Hippocampal formation and recognition memory}

Monkeys with neurotoxic hippocampal lesions showed a delaydependent recognition memory loss emerging at delays of $60 \mathrm{sec}$ on the VPC, while maintaining normal performance on DNMS, except for the $600 \mathrm{sec}$ distraction trials (type 3) (Fig. 11), a finding consistent with previous reports in monkeys (Pascalis and Bachevalier, 1999; Zola et al., 2000) and rodents (for review, see Mumby, 2001). Thus, the results suggest that VPC seems to be more sensitive to hippocampal lesions than DNMS (Clark et al., 2000; 2001; Pascalis and Bachevalier, 1999; Zola et al., 2000), a pattern of results also described in humans (McKee and Squire, 1993; Pascalis et al., 2000; Holdstock et al., 2002; Mayes et al., 2003).

Several reasons could account for the differential outcomes of hippocampal lesions on the two recognition tasks. The first is the relatively small extent of hippocampal damage in three of the four animals of the present study. Although no correlation was found between the extent of the lesion and VPC scores because of floor effects, the extent of hippocampal damage significantly correlated with performance at the longest DNMS delays of 120 and $600 \mathrm{sec}$. Thus, it is possible that more complete hippocampal damage might result in even greater DNMS impairment, an outcome not supported by a recent meta-analysis indicating that the more complete the hippocampal damage, the better the DNMS scores (Baxter and Murray, 2001). 


\section{TH/TF-3}
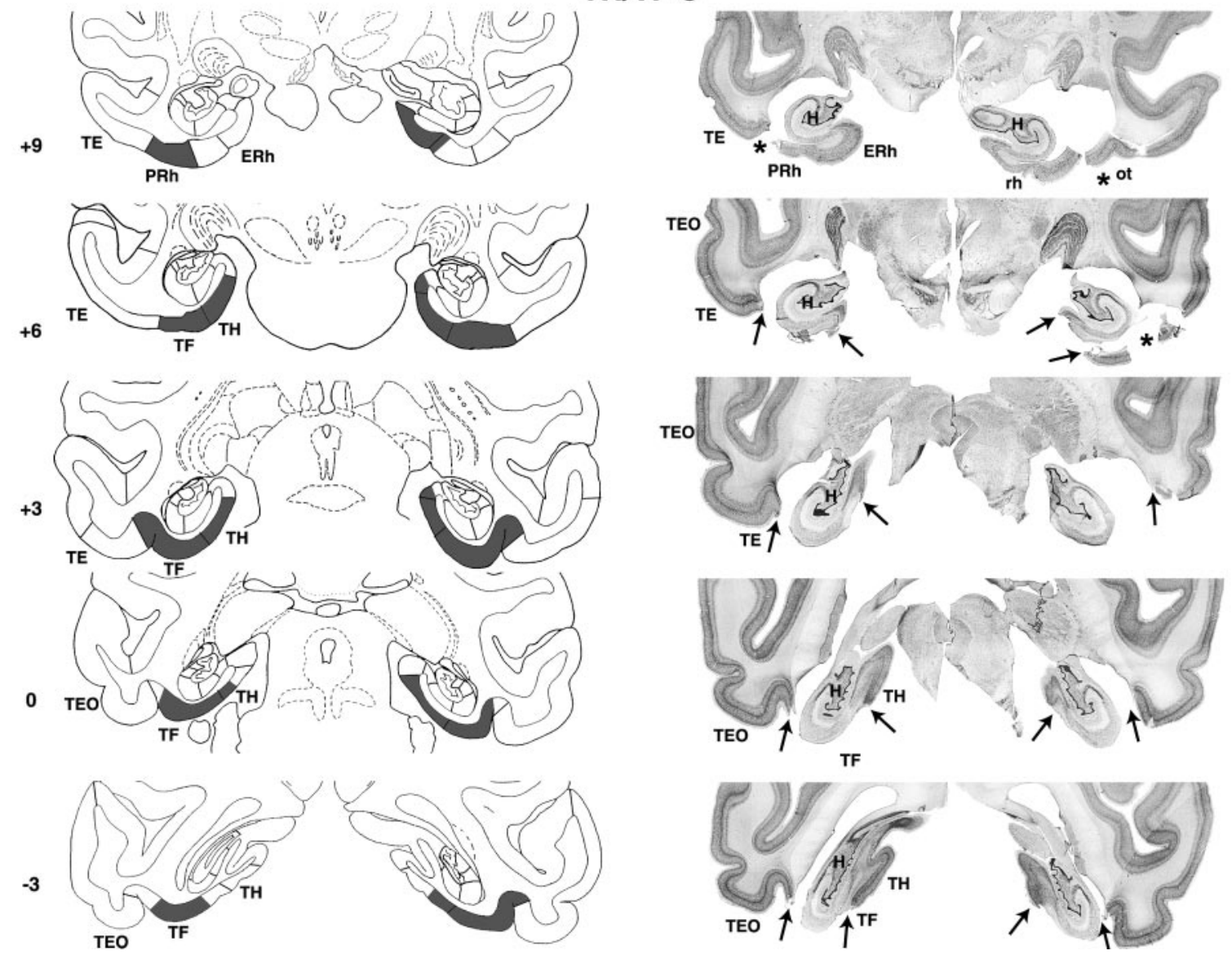

Figure 8. Coronal sections through areas TH and TF (left) and corresponding photomicrographs of thionin-stained coronal sections (right) of case TH/TF-3. Note that fiber damage just below areas TH/TF was seen on histological sections but not on the postsurgical T1-weighed MR images. The numerals on the left of each coronal section of the intended lesions indicate the distance in millimeters from the interaural plane. The asterisks point to unintended damage to adjacent structures. ERh, Entorhinal cortex; pmt, posterior middle temporal sulcus; rh, rhinal sulcus; ot, occipitotemporal sulcus; sts, superior temporal sulcus; TE, TEO, TH and TF, cytoarchitectonic fields described by von Bonin and Bailey (1947).

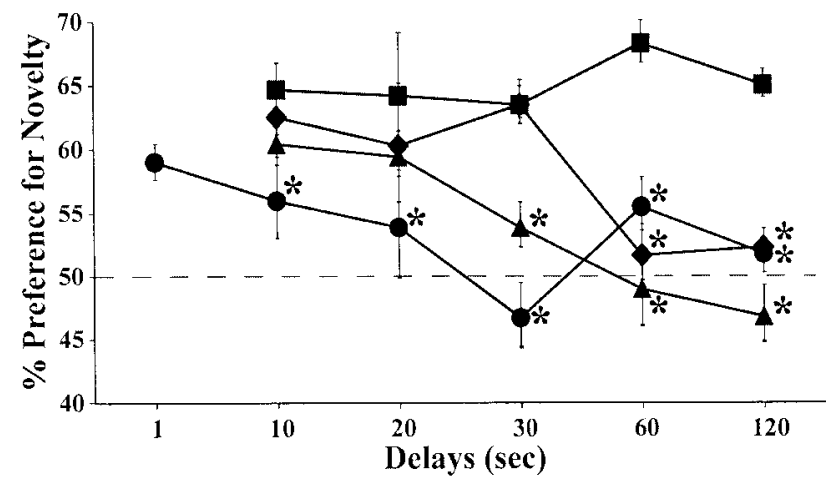

Figure 9. Average percentage of looking time at the novel stimulus during each delay condition of the VPC task for animals with hippocampal lesions ( ), animals with PRh lesions (-), animals with areas TH/TF lesions $(\boldsymbol{\Delta})$, and unoperated controls $(\boldsymbol{\square})$. The dashed horizontal line represents chance performance (50\%), and vertical bars for each data point indicate SEM. ${ }^{*} p<$ 0.05 , compared with controls.

Other potential factors relate to methodological differences. Presentation of the delays (intermixed for VPC vs sequential for DNMS) is unlikely to have affected the results, because both delay procedures yield similar DNMS performance in monkeys with either hippocampal lesions (Zola-Morgan and Squire, 1985) or fornix transections (Gaffan, 1977). However, there are several

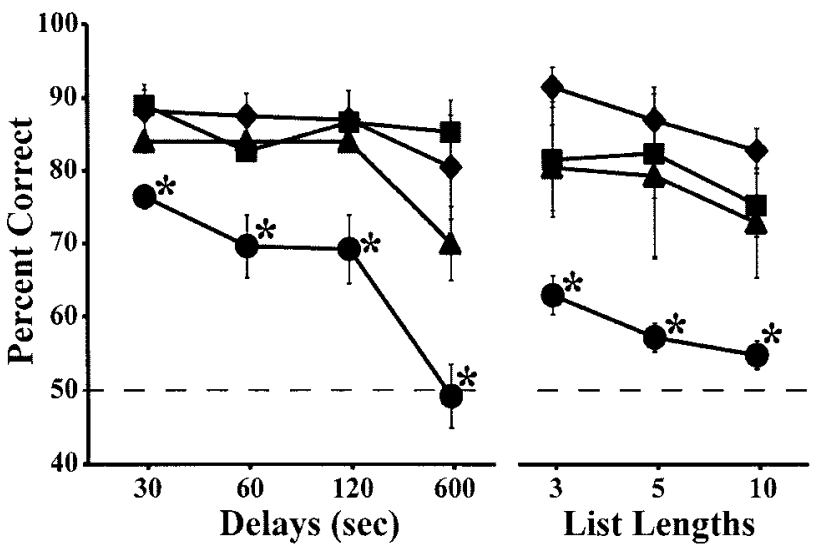

Figure 10. Average percentage of correct choices at the four delays (s-DNMS) and three lists (I-DNMS) of the DNMS task for each animal group. $\bullet$, Animals with hippocampal lesions; animals with PRh lesions; $\boldsymbol{\Lambda}$, animals with areas TH/TF lesions; $\boldsymbol{\square}$, unoperated controls. The dashed horizontal line represents chance performance (50\%), and vertical bars for each data point indicate SEM. ${ }^{*} p<0.05$, compared with controls.

reasons to believe that the presence of food reward (DNMS) or the absence of it (VPC) could affect the animals' performance (Gaffan et al., 1984). In contrast to passively viewing stimuli for VPC, food-deprived animals actively commit the sample object 

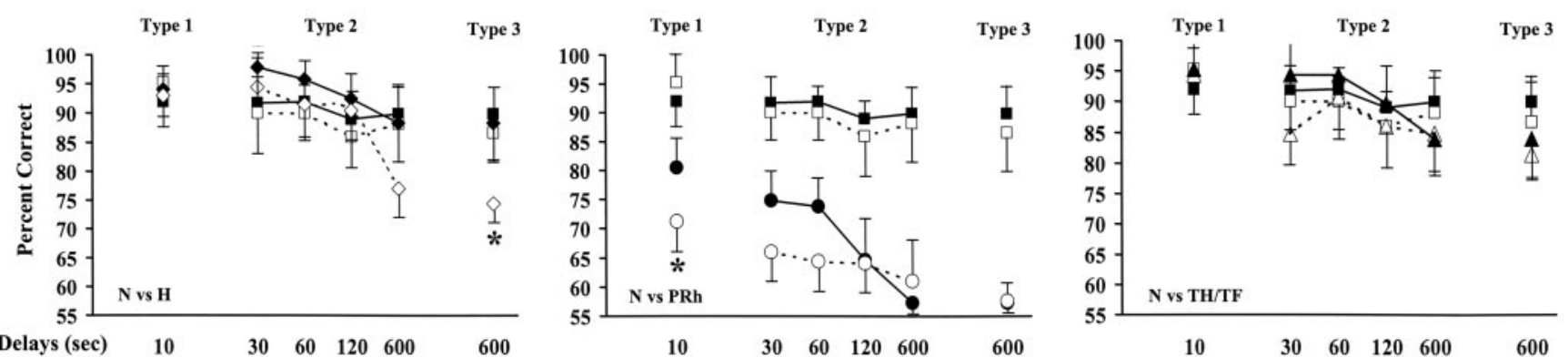

Figure 11. Average percentage of correct choices in the standard (solid line) and distraction (dashed line) trials of the dDNMS for each distraction type in the four animal groups. hippocampal lesions; $\mathbf{O}$, animals with PRh lesions; $\mathbf{\Lambda}$, animals with areas TH/TF lesions; $\mathbf{\square}$, unoperated controls. The dashed horizontal line represents chance performance (50\%), and vertical bars for each data point indicate SEM. ${ }^{*} p<0.05$, compared with controls.

Table 4. Delayed nonmatching-to-sample task: test-retest effect

\begin{tabular}{|c|c|c|c|c|c|c|c|c|c|c|}
\hline \multirow[b]{2}{*}{ Case } & \multicolumn{4}{|c|}{ Test 1} & \multirow[b]{2}{*}{ Avg } & \multicolumn{4}{|c|}{ Test 2} & \multirow[b]{2}{*}{ Avg } \\
\hline & 30 & 60 & 120 & 600 & & 30 & 60 & 120 & 600 & \\
\hline \multicolumn{11}{|l|}{ Group N } \\
\hline $\mathrm{N}-1$ & 90 & 84 & 88 & 82 & 86.0 & 91 & 89 & 89 & 94 & 90.8 \\
\hline $\mathrm{N}-2$ & 92 & 81 & 85 & 94 & 88.0 & 98 & 95 & 93 & 93 & 94.8 \\
\hline $\mathrm{N}-3$ & 85 & 83 & 87 & 80 & 83.8 & 86 & 92 & 85 & 83 & 86.5 \\
\hline$x$ & 89 & 83 & 87 & 85 & 85.9 & 92 & $92^{* *}$ & 89 & 90 & $90.7^{* *}$ \\
\hline \multicolumn{11}{|l|}{ Group H } \\
\hline $\mathrm{H}-1$ & 84 & 82 & 76 & 64 & 76.5 & 96 & 94 & 88 & 90 & 92.0 \\
\hline $\mathrm{H}-2$ & 89 & 83 & 88 & 74 & 83.5 & 99 & 95 & 93 & 70 & 89.3 \\
\hline $\mathrm{H}-4$ & 98 & 95 & 95 & 96 & 96.0 & 100 & 100 & 96 & 93 & 97.3 \\
\hline $\mathrm{H}-5$ & 82 & 90 & 89 & 88 & 87.3 & 96 & 94 & 93 & 100 & 95.8 \\
\hline$x$ & 88 & 88 & 87 & 81 & 85.8 & $98^{*}$ & $96^{*}$ & 93 & 88 & $93.6^{* *}$ \\
\hline \multicolumn{11}{|l|}{ Group PRh } \\
\hline PRh-1 & 73 & 64 & 56 & 50 & 60.8 & 71 & 67 & 53 & 57 & 61.9 \\
\hline PRh-2 & 74 & 58 & 62 & 50 & 61.0 & 72 & 68 & 66 & 53 & 64.8 \\
\hline PRh-3 & 77 & 80 & 79 & 38 & 68.5 & 81 & 87 & 61 & 57 & 71.4 \\
\hline PRh-4 & 81 & 79 & 80 & 64 & 76.0 & 83 & 85 & 85 & 63 & 79.1 \\
\hline PRh-5 & 77 & 67 & 69 & 44 & 64.3 & 67 & 62 & 58 & 57 & 60.9 \\
\hline$x$ & 76 & 70 & 69 & 49 & 66.1 & 75 & 74 & 65 & $57^{* *}$ & 67.6 \\
\hline \multicolumn{11}{|l|}{ Group TH/TF } \\
\hline TH/TF-1 & 87 & 86 & 85 & 74 & 83.0 & 98 & 94 & 91 & 83 & 91.5 \\
\hline TH/TF-2 & 82 & 84 & 85 & 76 & 81.8 & 95 & 93 & 98 & 97 & 95.7 \\
\hline TH/TF-3 & 83 & 82 & 82 & 60 & 76.8 & 90 & 96 & 80 & 73 & 84.6 \\
\hline$x$ & 84 & 84 & 84 & 70 & 80.5 & $94^{*}$ & $94^{*}$ & 90 & $84^{*}$ & $90.6^{*}$ \\
\hline
\end{tabular}

Scores at each delay are the percentage of correct responses during standard DNMS trials when administered first separately (test 1) in the DNMS task and when subsequently administered mixed with distraction trials (test 2) in the DNMS with distraction. Symbols denote within-group improvement on test 2 relative to test 1 (paired $t$ tests: ${ }^{*} p \leq 0.05 ;{ }^{* *} p \leq 0.08$ ). Avg, Average.

to memory in DNMS, for they know that this information will be necessary to later obtain an additional food-reward. Thus, in the absence of a functional hippocampus, the incentive of food rewards in DNMS might strongly motivate the operated animals to develop alternative strategies to maintain the memory of an object for a few minutes, despite their recognition memory impairment. This possibility was directly tested by the systematic introduction of distractors during the delay periods of DNMS. At the longest delay of $600 \mathrm{sec}$, the performance of group $\mathrm{H}$ deteriorated with intervening distractors, even more so after a context change for the entire $600 \mathrm{sec}$ period than by performance on a shortlasting motor task. This susceptibility to proactive interference after hippocampal damage has already been reported by others [Owen and Butler, 1981; but for different results, see BeasonHeld et al. (1999) and Zola et al. (2000)] and suggests that, at delays lasting more than a few minutes, monkeys with hippocampal damage may be using active, distraction-sensitive strategies (e.g., working memory or retrospective processing) to perform well on DNMS despite their impaired recognition memory in VPC.
Parahippocampal cortex (TH/TF) and recognition memory Damage to areas TH/TF significantly impaired VPC performance ( $\geq 30 \mathrm{sec}$ delay) and mildly, but transiently, disrupted DNMS acquisition, indicating that, in addition to contribute to spatial memory (for review, see Málková and Mishkin, 2003), areas $\mathrm{TH} / \mathrm{TF}$ are critical for item-specific recognition memory. These findings are consistent with previous behavioral (Georges et al., 1989) and electrophysiological (Riches et al., 1991; Salzmann et al., 1993) studies. Nevertheless, investigations of the effects of fiber-sparing neurotoxic lesion of these cortical areas will be necessary to ascertain whether or not the item-specific recognition impairment after areas TH/TF could be associated with indirect, even relatively small, transection of fibers traveling from visual areas V4 and TE to PRh more rostrally (Suzuki, 1996). In addition, given that saccadic eye movements (even in complete darkness) modulate TH/TF neuron activity (Ringo et al., 1994; Nowicka et al., 1995; Sobotka et al., 1997), it remains possible that the increase in saccadic eye movements found after TH/TF lesions could have affected the way in which the operated monkeys 
explored the stimuli, resulting in poor recognition specifically when long temporal gaps needed to be bridged $(\geq 30 \mathrm{sec})$.

\section{Is recognition memory distributed across a functionally unitary medial temporal lobe system?}

Although clear-cut double dissociations between tasks and lesions were not found in the present study, the different outcomes of the three lesion types on VPC and DNMS indicate that these areas could largely (albeit not exclusively) mediate different recognition memory processes. It has been shown that PRh cortex is involved in perceptual discrimination of objects composed of ambiguous features (Buckley et al., 2001; Bussey et al., 2002), in short-term memory (Buffalo et al., 2000) and in coding different forms of stimulus associations (Liu et al., 2000; Messinger et al., 2001; Naya et al., 2003). In addition, the parahippocampal cortices seem to be more critical for object-place associations (Málková and Mishkin, 2003), whereas the hippocampal formation seems to mediate the retrieval of contextual associative information (Cohen and Eichenbaum, 1995; Mishkin et al., 1998; Brown and Aggleton, 2001; O'Reilly and Rudy, 2001).

In VPC, animals are passively exploring two-dimensional black/white novel stimuli, not actively memorizing the sample to select a future response (i.e., incidental learning). It is presumably more ecological for monkeys (and humans) passively witnessing a new event to keep a trace (however weak it is) of the whole event, because anything can later prove to be behaviorally relevant (i.e., the stimulus, its elements, and its spatial and temporal contexts). This incidental encoding could favor the formation of conjunctive representation not only of the different elements of the sample but also of its location and contexts (O'Reilly and Rudy, 2001). Given the distinctive roles of the three structures listed above, it is perhaps not surprising that all three may be recruited during incidental learning in VPC and may interact to permit memory of the sample (Manns et al., 2000; Stark et al., 2002).

Conversely, for DNMS, the animals actively displace sample objects (varying widely in size, shape, color, and texture), which could facilitate the distinction between stimulus and background, hence, the formation of a representation of the object itself, irrespective of its spatial location or context. Also, DNMS involves intentional (purposeful) encoding. Thus, recognition might rely more on memory of the sample itself and less on memory of its location and context. Viewed in this way, the PRh cortex could be more critically involved in the DNMS task than the parahippocampal cortex and hippocampal formation.

In summary, similar deficits on both tasks in the case of PRh lesions suggest that this temporal cortical area might contribute more to associations between items than to recollection of spatial and contextual information. Conversely, impairment at long delays of VPC combined with DNMS impairment when contextual distractors intervene in the case of hippocampal lesions might support the view that this structure relies preferentially on retrieval of contextual information than on item associations. Finally, increased saccadic eye movements and recognition impairment almost exclusively in VPC after area TH/TF lesions suggest that these areas may be recruited to bring the subject's attention to various perceptual features of stimuli and their location in space. Thus, as already shown by others (Gaffan, 1994; Buckley et al., 1997), recognition memory emerges from cooperative interactions among relatively specialized medial temporal structures. This view is further supported by a recent neuroimaging study in humans (Düzel et al., 2003) as well as by our most recent findings showing that damage to these three structures also impaired the learning of a transverse patterning problem, a task that relies heavily on associations between items (Alvarado et al., 1998; Alvarado and Bachevalier, 2003).

\section{References}

Alvarado MC, Bachevalier J (2003) Damage to perirhinal and parahippocampal TH/TF cortices in monkeys impairs performance on transverse patterning. Soc Neurosci Abstr 29:324.3.

Alvarado MC, Mishkin M, Bachevalier J (1998) Neurotoxic lesions of the hippocampal formation impair monkeys' acquisition of the transverse patterning. Soc Neurosci Abstr 24:928.

Bachevalier J, Nemanic S, Alvarado MC (2002) The medial temporal lobe structures and object recognition memory in nonhuman primates. In: Neuropsychology of memory, Ed 2 (Squire LR, Schacter DL, eds), pp 326-338. New York: Guilford.

Baxter MG, Murray EA (2001) Opposite relationship of hippocampal and rhinal cortex damage to delayed nonmatching-to-sample deficits in monkeys. Hippocampus 11:61-71.

Beason-Held LL, Rosene DL, Killiany RJ, Moss MB (1999) Hippocampal formation lesions produce memory impairment in the rhesus monkey. Hippocampus 9:562-574.

Blaizot X, Landeau B, Baron JC, Chavoix C (2000) Mapping the visual recognition memory network with PET in the behaving baboon. J Cereb Blood Flow Metab 20:213-219.

Brown MW, Aggleton JP (2001) Recognition memory: what are the roles of the perirhinal cortex and hippocampus? Nat Rev Neurosci 2:51-61.

Buckley MJ, Gaffan D (1998) Perirhinal cortex ablation impairs visual object identification. J Neurosci 18:2268-2275.

Buckley MJ, Gaffan D, Murray EA (1997) Functional double dissociation between two inferior temporal cortical areas: perirhinal cortex versus middle temporal gyrus. J Neurophysiol 77:587-598.

Buckley MJ, Booth MC, Rolls ET, Gaffan D (2001) Selective perceptual impairments after perirhinal cortex ablation. J Neurosci 21:9824-9836.

Buffalo EA, Ramus SJ, Clark RE, Teng E, Squire LR, Zola SM (1999) Dissociation between the effects of damage to perirhinal cortex and area TE. Learn Mem 6:572-599.

Buffalo EA, Ramus SJ, Squire LR, Zola SM (2000) Perception and recognition memory in monkeys following lesions of area TE and perirhinal cortex. Learn Mem 7:375-382.

Bussey TJ, Saksida LM (2002) The organization of visual object representations: a connectionist model of effects of lesions in perirhinal cortex. Eur J Neurosci 15:355-364.

Chavoix C, Blaizot X, Meguro K, Landeau B, Baron JC (2002) Excitotoxic lesions of the rhinal cortex in the baboon differentially affect visual recognition memory, habit memory and spatial executive functions. Eur J Neurosci 15:1225-1236.

Clark RE, Teng E, Squire LR, Zola SM (1997) Perirhinal damage impairs memory on the visual paired-comparison task. Soc Neurosci Abstr 23:12.

Clark RE, West AN, Zola SM, Squire LR (2001) Rats with lesions of the hippocampus are impaired on the delayed nonmatching-to-sample task. Hippocampus 11:176-186.

Clark RE, Zola SM, Squire LR (2000) Impaired recognition memory in rats after damage to the hippocampus. J Neurosci 20:8853-8860.

Cohen NJ, Eichenbaum H (1995) Memory, amnesia and the hippocampal system. Cambridge, MA: MIT.

Davachi L, Goldman-Rakic PS (2001) Primate rhinal cortex participates in both visual recognition and working memory tasks: functional mapping with 2-DG. J Neurophysiol 85:2590-2601.

Düzel E, Habib R, Rotte M, Guderian S, Tulving E, Heinze H-J (2003) Human hippocampal and parahippocampal activity during visual associative recognition memory for spatial and nonspatial stimulus configurations. J Neurosci 23:9439-9444.

Gaffan D (1977) Recognition memory after short retention intervals in fornix-transected monkeys. Q J Exp Psychol 29:577-588.

Gaffan D (1994) Dissociated effects of perirhinal cortex ablation, fornix transection and amygdalectomy: evidence for multiple memory systems in the primate temporal lobe. Exp Brain Res 99:411-422.

Gaffan D, Shields C, Harrison S (1984) Delayed matching by fornixtransected monkeys: the sample, the push and the bait. Q J Exp Psychol B 36:305-317.

George PJ, Horel JA, Cirillo RA (1989) Reversible cold lesions of the para- 
hippocampal gyrus in monkeys result in deficits on the delayed matchto-sample and other visual tasks. Behav Brain Res 34:163-178.

Hodos W, Bobko PA (1984) A weighted index of bilateral brain lesions. J Neurosci Methods 12:43-47.

Holdstock JS, Mayes AR, Roberts N, Cezayirli E, Isaac CL, O'Reilly RC, Norman KA (2002) Under what conditions is recognition spared relative to recall after selective hippocampal damage in humans? Hippocampus 12:341-351.

Liu Z, Murray EA, Richmond BJ (2000) Learning motivational significance of visual cues for reward schedules requires rhinal cortex. Nat Neurosci 3:1307-1315.

Málková L, Mishkin M (2003) One-trial memory for object-place associations after separate lesions of hippocampus and posterior parahippocampal region in the monkey. J Neurosci 23:1956-1965.

Málková L, Bachevalier J, Mishkin M, Saunders RC (2001a) Neurotoxic lesions of perirhinal cortex impair visual recognition memory in rhesus monkeys. NeuroReport 12:1913-1917.

Málková L, Lex CK, Mishkin M, Saunders RC (2001b) MRI-based evaluation of locus and extent of neurotoxic lesions in monkeys. Hippocampus 11:361-370.

Manns JR, Stark CEL, Squire LR (2000) The visual paired-comparison task as a measure of declarative memory. Proc Natl Acad Sci USA 97:12375-12379.

Manns JR, Reed JM, Squire LR (2003) Recognition memory and the human hippocampus. Neuron 37:171-180.

Mayes AR, Holdstock JS, Isaac CL, Hunkin NM, Roberts N (2003) Relative sparing of item recognition memory in a patient with adult-onset damage limited to the hippocampus. Hippocampus 12:325-340.

McKee RD, Squire LR (1993) On the development of declarative memory. J Exp Psychol Learn Mem Cogn 19:397-404.

Messinger A, Squire LR, Zola SM, Albright TD (2001) Neuronal representation of stimulus associations develop in the temporal lobe during learning. Proc Natl Acad Sci USA 98:12239-12244.

Meunier M, Bachevalier J, Mishkin M, Murray EA (1993) Effects on visual recognition of combined and separate ablations of the entorhinal and perirhinal cortex in rhesus monkeys. J Neurosci 13:5418-5432.

Miller EK, Desimone R (1994) Parallel neuronal mechanisms for shortterm memory. Science 263:520-522.

Miller EK, Li L, Desimone R (1991) A neural mechanism for working and recognition memory in inferior temporal cortex. Science 254:1377-1379.

Mishkin M, Vargha-Khadem F, Gadian DG (1998) Amnesia and the organization of the hippocampal system. Hippocampus 8:212-216.

Mumby DG (2001) Perspectives on object-recognition memory following hippocampal damage: lessons from studies in rats. Behav Brain Res 127:159-181.

Murray EA (2000) Memory for objects in nonhuman primates. In: The new cognitive neurosciences (Gazzaniga MS, ed), pp 753-764. Cambridge, MA: MIT.

Murray EA, Richmond BJ (2001) Role of perirhinal cortex in object perception, memory, and associations. Curr Opin Neurobiol 11:188-193.

Naya Y, Yoshida M, Miyashita Y (2001) Backward spreading of memoryretrieval signal in the primate temporal cortex. Science 291:661-664.

Nemanic S, Alvarado MC, Price RE, Jackson EF, Bachevalier J (2002) Assessment of locus and extent of neurotoxic lesions in monkeys using neuroimaging techniques: a replication. J Neurosci Methods 121:199-209.

Nowicka A, Ringo JL, O’Neill S (1995) Saccadic eye movements (SEMs) enhance stimulus specific adaptation in inferotemporal (IT) units of macaque. Soc Neurosci Abstr 21:661.

O'Reilly RC, Rudy JW (2001) Conjunctive representations in learning an memory: Principles of cortical and hippocampal function. Psychol Rev 108:311-345.

Owen MJ, Butler SR (1981) Amnesia after transection of the fornix in monkeys: long-term memory impaired, short-term memory intact. Behav Brain Res 3:115-123.

Pascalis O, Bachevalier J (1999) Neonatal aspiration lesions of the hippocampal formation impair visual recognition memory when assessed by paired-comparison task but not by delayed nonmatching-to-sample task. Hippocampus 9:609-616.

Pascalis O, Hunkin NM, Holdstock JS, Isaac CL, Mayes AR (2000) Differential performance on recognition memory tests and the visual paired comparison task in a patient with selective hippocampal lesion. Soc Neurosci Abstr 26:1241.

Riches IP, Wilson FAW, Brown MW (1991) The effects of visual stimulation and memory on neurons of the hippocampal formation and the neighboring parahippocampal gyrus and inferior temporal cortex of the primate. J Neurosci 11:1763-1779.

Ringo JL, Sobotka S, Diltz MD, Bunce CM (1994) Eye movements modulate activity in hippocampal, parahippocampal, and inferotemporal neurons. J. Neurophysiol 71:1285-1288.

Salzmann E, Vidyasagar TR, Creutzfeldt OD (1993) Functional comparison of neuronal properties in the primate posterior hippocampus and parahippocampus (area TF/TH) during different behavioural paradigms in volving memory and selective attention. Behav Brain Res 53:133-149.

Sobotka S, Nowicka A, Ringo JL (1997) Activity linked to externally cued saccades in single units recorded from hippocampal, parahippocampal and inferotemporal areas of macaques. J Neurophysiol 78:2156-2163.

Stark CEL, Bayley PJ, Squire LR (2002) Recognition memory for single items and for associations is similarly impaired following damage to the hippocampal region. Learn Mem 9:238-242.

Suzuki WA (1996) Neuroanatomy of the monkey entorhinal, perirhinal and parahippocampal cortices: organization of cortical inputs and interconnections with amygdala and striatum. Neurosciences 8:3-12.

Tulving E (1985) Memory and consciousness. Can Psychol 26:1-12.

von Bonin G, Bailey P (1947) The neocortex of Macaca mulatta. Urbana, IL: University of Illinois.

Wan H, Aggleton JP, Brown MW (1999) Different contributions of the hippocampus and perirhinal cortex to recognition memory. J Neurosci 19:1142-1148.

Xiang JZ, Brown MW (1998) Differential neuronal encoding of novelty, familiarity and recency in regions of the anterior temporal lobe. Neuropharmacology 37:657-676.

Yonelinas AP (2002) The nature of recollection and familiarity: a review of 30 years of research. J Mem Language 46:441-517.

Zhu XO, McCabe BJ, Aggleton JP, Brown MW (1996) Mapping visual recognition memory through expression of the immediate early gene c-fos. NeuroReport 7:1871-1875.

Zola SM, Squire LR, Teng E, Stefanacci L, Buffalo EA, Clark SK (2000) Impaired recognition memory in monkeys after damage limited to the hippocampal region. J Neurosci 20:451-463.

Zola-Morgan S, Squire LR (1985) Medial temporal lesions in monkeys impair memory on a variety of tasks sensitive to human amnesia. Behav Neurosci 99:22-34. 